\title{
Chapter
}

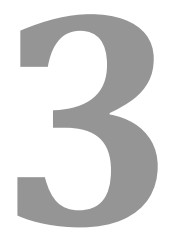

\section{NEW PROMISING BIODEGRADABLE POLYESTERS DERIVED FROM POLY $((R, S)-3,3$-DIMETHYLMALIC ACID) FOR CARDIOVASCULAR APPLICATIONS}

\section{Rima Belibel and Christel Barbaud*}

INSERM U1148, Laboratory for Vascular Translational Science (LVTS), Institut Galilée, Université Paris 13, Sorbonne Paris Cité, 99 Avenue Jean-Baptiste Clément, Villetaneuse, F-93430, France 


\section{Contents}

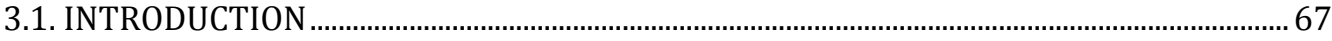

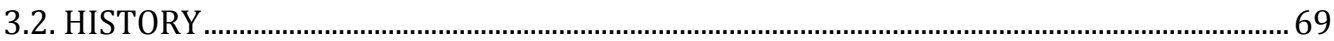

3.3. INTERESTS AND APPLICATION OF PDMMLAs............................................................................. 72

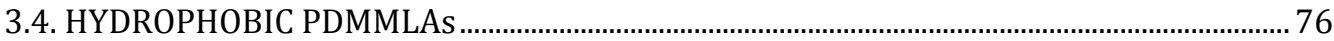

3.4.1. Synthesis of hydrophobic PDMMLAs ....................................................................... 76

3.4.2. Physicochemical characterization of hydrophobic PDMMLAs ............................... 78

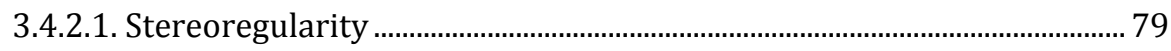

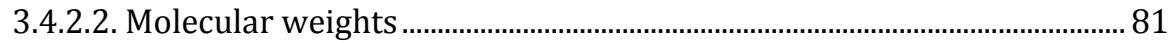

3.4.2.3. Thermal properties: semi-crystallinity $\left(T_{\mathrm{m}}\right)$, crystallization temperature $\left(T_{\mathrm{c}}\right)$, glass-transition temperature $\left(T_{\mathrm{g}}\right)$, and

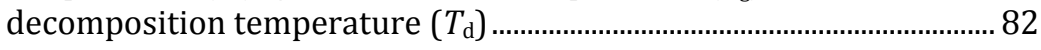

3.5. HYDROPHILIC/HYDROPHOBIC PDMMLAs .......................................................................... 86

3.5.1. Synthesis and chemical characterization of hydrophilic/hydrophobic

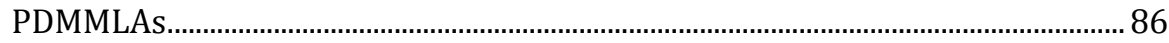

3.5.2. Physicochemical properties and surface characterization of PDMMLAs ........... 88

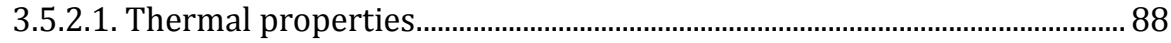

3.5.2.2. Surfaces roughness and topography....................................................... 89

3.5.2.3. Surfaces wettability and water sorption/desorption................................. 90

3.5.2.4. Surfaces free energy and its components .................................................. 93

3.5.3. In vitro biodegradation rate and nature of PDMMLAs and the cytotoxicity of degradation products ......................................................................... 94

3.5.3.1. Degradation of homopolymers: effect of load and nature of functional side chain and biological enzymes ............................................ 95

3.5.3.2. Degradation of copolymers: effect of molecular weight, enzymes, pH, and temperature ..................................................................... 96

3.5.3.3. Cytotoxicity of PDMMLAs degradation products.....................................100

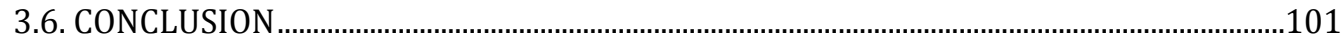

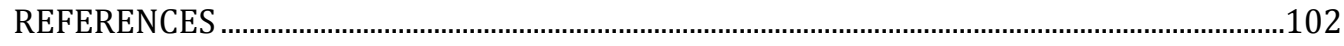




\subsection{INTRODUCTION}

Biopolyesters are widely recommended in biomedical applications [1] as drug carriers [2] such as poly(L-lactic acid) (PLA), poly(glycolic acid) (PGA), poly( $\varepsilon$ -caprolactone) (PCL) [3], and poly(malic acid) (PMLA) [4-8]. These biodegradable polyesters were used either alone or as copolymers side chains to improve their mechanical properties, hydrolysis, long-term biodegradation, or biocompatibility behavior for the desired therapeutic applications (PLGA [9,10], PLMA [11-15], etc.). Among this class of polymers, the PMLA is known to present good biocompatibility, non-toxicity in vitro and in vivo, non-immunogenic properties, and stability in the bloodstream [5,16-19]. The particularity of this family of polyesters is the presence of functionalized groups in their side chain which, furthermore, allow chemical modification for grafting, thus delivering drugs [20].

These biopolyesters are widely studied for anchoring soft tissue to bone, in tissue regeneration and in the cardiovascular field as implants, valves, support for cells in tissue regeneration, and passive or active coating for coronary stents. Therefore, certain active stents made of these biomaterials have been commercialized (Supralimus, BioMime, Nobori, etc.) [21]. Indeed, these materials associated with antiproliferative molecules have enabled a significant reduction in restenosis rates. However, these devices do not have a complete satisfaction [22]. In point of fact, the results of clinical studies presented an increased rate of very late stent thrombosis [23,24]. This is mainly due to two leading pathophysiological mechanisms [25]: the delayed healing of the endothelium [26,27] and the proinflammatory process of the used polymers [28-30]. Furthermore, some physicochemical properties of the used polymers coatings (crystallinity, hydrophobicity, high glass temperature ( $\mathrm{Tg}$ ) and too slow degradation rate, etc.) limit their use. In these circumstances, many problems, at the coating adhesion to the metal, can be encountered as well as adhesion of cells on the polymer surface after deployment and placement of the stent at the lesion [31-36]. Cracks and failures of polymer coating may occur. Consequently, it poses a risk of endothelial damage and corrosion of the surface of the material (release of particles, ions, and oligomers in the biological environment) and induces so late thrombosis.

The development of the appropriate biomaterial which has good mechanical properties and good cells behavior, delivers a drug, and degrades completely is the challenge of scientific and medical research in the last decade.

The surface of the polymer coating is defined by its external part which is in direct contact with blood. The biocompatibility of these polymers is generally modulated by its chemical composition in particular by varying their hydrophilic/hydrophobic ratio. They allow also the chemical modification of polymer. Moreover, the interaction between the biomaterial and the body is 
located on its surface. To understand the biomaterials interaction with biological environment, the study of their surface properties is paramount. In addition, the biological response is characterized by the nature of the biomaterial/cell interactions. Indeed, the cells adhesion, morphology, and proliferation involved in these interactions depend on several factors. These factors include the chemical composition and the material charge, its roughness and morphology, surface wettability and hydrophilic/hydrophobic behavior, and the surface energy of the material.

With the exception of PMLA, the other mentioned polyesters are uncharged and hydrophobic, giving them a poor wettability. Therefore, the surface of a hydrophobic material is physically or chemically modified to promote cell adhesion and proliferation $[37,38]$. PMLA has many interesting properties, in addition to its functionalisable properties, such as non-toxicity in vitro and in vivo, non-immunogenicity, biodegradability, stability in the bloodstream, and cell affinity [39-43]. However, its application is limited because of the synthesis conditions (time and cost) and transfer reactions during its chemical synthesis and/or modification [18,44-53].

For this reason, poly $((R, S)$-3,3-dimethylmalic acid) (PDMMLA) derivatives which are part of the PMLA family are new biodegradable and biocompatible polyesters prepared for an eventual use for cardiovascular applications to cover a coronary stent, thus delivering drugs. They can be custom-synthesized to meet adequate physicochemical and biological properties. In addition, its structural design was chosen to give natural and non-toxic primary products after a complete degradation. Therefore, the functional groups in their side chain which incorporated during the polymer synthesis are the carboxylic acid group $(-\mathrm{COOH})$ and the alcohol group $(-\mathrm{OH})$ which allow the chemical modification of polymer and bring acidic and neutral hydrophilic characters, respectively, and the hexylic group which provides hydrophobic character for PDMMLA polymers. Moreover, $-\mathrm{OH}$ functions were known for their opsonization phenomenon and their excellent blood compatibility and resistance to thrombus formation and carboxylic groups for their favorite cell attachment and proliferation [54].

This chapter introduces, in the first section, the history, interests, and applications in biomedical field of PDMMLAs family. The second section presents the synthesis of a series of isotactic homopolymers and copolymers and the characterization of their chemical and physicochemical properties. A comparative study of physicochemical properties of amorphous and semicrystalline PDMMLAs is also described. In the last section, the synthesis of amorphous PDMMLAs, the characterization of their surface physicochemical properties (rigidity, roughness, wettability, surface free energy, etc.), and the study of their biodegradation and cytotoxicity are detailed. 


\subsection{HISTORY}

Designing tailored macromolecular materials is crucially important to obtain novel specific applications and strictly adapt structures to specific targeted properties. Over the past three decades, the design of new synthetic approaches to the original macromolecular backbones was possible for the development of multimeric functionalized copolyesters. Novel chemical, chemoenzymatic, and biological routes have been established, leading to an extended family of poly( $\beta$-hydroxyacids). Thus, in addition to bacterial polyesters, new polymers obtained by copolymerization and chemical modification of poly( $\beta$-malic acid) (PMLA) were prepared (Figure 1) [55-58].

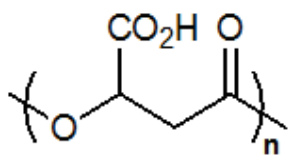

Figure 1. PMLA structure

The poly $(\beta$-malic acid) has been the subject of several research themes for various temporary therapeutic applications thanks to its good properties. This water soluble polyester is biodegradable, bioassimilable, non-toxic, nonimmunogenic, and biocompatible. It has the advantage of being metabolized in malic acid which is found in the Krebs cycle and is completely biodegraded in carbon and water [59]. The PMLA and benzyl derivative (PMLABn) are known since the late 1970s but their synthesis and applications are limited [59-65]. Since these years, all PMLA derivatives were obtained by ring-opening polymerization of various $\beta$-substituted $\beta$-lactones themselves synthesized from either malic acid or aspartic acid in several stages [60,66-68]. This synthesis has facilitated preparing a wide variety of monomers. It was a clear advantage compared to biodegradable polyesters such as PLA, PGA, and PCL, because it would allow researchers to synthesize a variety of polyesters derived from malic acid. Indeed, the possibility of having different pendant groups in the polyester structure (neutral, hydrophilic, reactive, etc.) and randomly distributed on the backbone allowed modulating solubility and degradation rate [69-71]. So, associating polymers, hydrogels, degradation micelles, macromolecular prodrugs, graft polyesters, and bioactive compounds has been synthesized and characterized [72-75]. Only during the synthesis of the various homopolymers and copolymers, it was difficult to obtain controlled high molecular weights. Moreover, it was impossible to synthesize block copolymers because the anionic ring-opening polymerization did not correspond to a living polymerization process. Under $1 \mathrm{H}$ nuclear magnetic resonance (NMR) spectroscopic analysis of the polymers, the presence on the spectrum of a small doublet systematically appeared and corresponded to the 
formation of a $\mathrm{C}=\mathrm{C}$ double bond [76]. It has been shown that during the anionic polymerization initiated by weak bases such as tetraalkylammonium benzoates, transfer reactions due to the presence of a proton in $\beta$-position of the carbonyl of the lactone were observed [77]. Therefore, we could predicate two synthetic routes, which limited the expected molecular masses of polymers (Scheme 1). Discrepancies between measured and theoretical molecular weights have been observed and the molecular weight distribution was larger than expected.
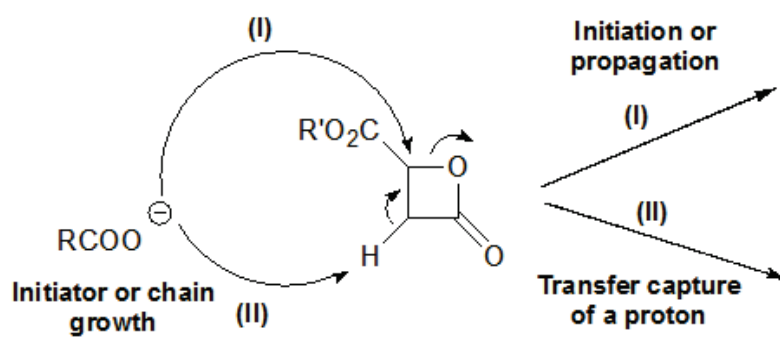<smiles>O=C(O)CC(C(=O)O)C(=O)O</smiles>

Scheme 1. Mechanism of transfer reaction

Following this finding at the beginning of the 2000s, a study was directed towards the modification of the structure of malolactonic acid esters considering replacing the two protons in $\alpha$-position of the carbonyl of the lactone with different alkyls (methyl, allyl, etc.). To find the ideal structure of the monomer, a thorough research on the various known metabolisms resulted in the existence of the biosynthesis of pantothenate and Coenzyme A from $(R)$ -3,3-dimethylmalic acid [78-80]. As this (R)-3,3-dimethylmalic acid is a natural and non-toxic compound, a new study was directed towards the synthesis of $\alpha, \alpha, \beta$-trisubstituted $\beta$-lactones completely unreported. These new lactones could then be polymerized without observing transfer reactions in the aim to obtain this new family of polyester named poly $((R, S)$-3,3-dimethylmalic acid) (PDMMLA) (Figure 2) [81,82].

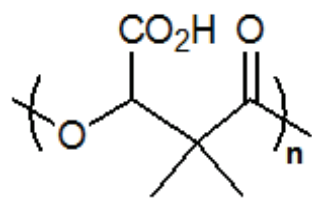

Figure 2. Structure of PDMMLA

Initially, the total synthesis of these $\alpha, \alpha^{\prime}, \beta$-trisubstituted $\beta$-lactones has been developed. Firstly, racemic monomers have been prepared in five steps from 
the commercial racemic diethyl oxalpropionate $[81,83,84]$. The first step is alkylation. It is followed by reduction of the ketone function to the alcohol and a basic hydrolysis to provide intermediate diacid which is then monoesterified with various alcohols according to the desired therapeutic application of the final polyester $[85,86]$. The various monoesters are then lactonized according to Mitsunobu reaction to obtain the corresponding racemic $\alpha, \alpha^{\prime}, \beta$ -trisubstituted $\beta$-lactones (Scheme 2) which were polymerized to obtain amorphous and atactic polyesters $[87,88]$.

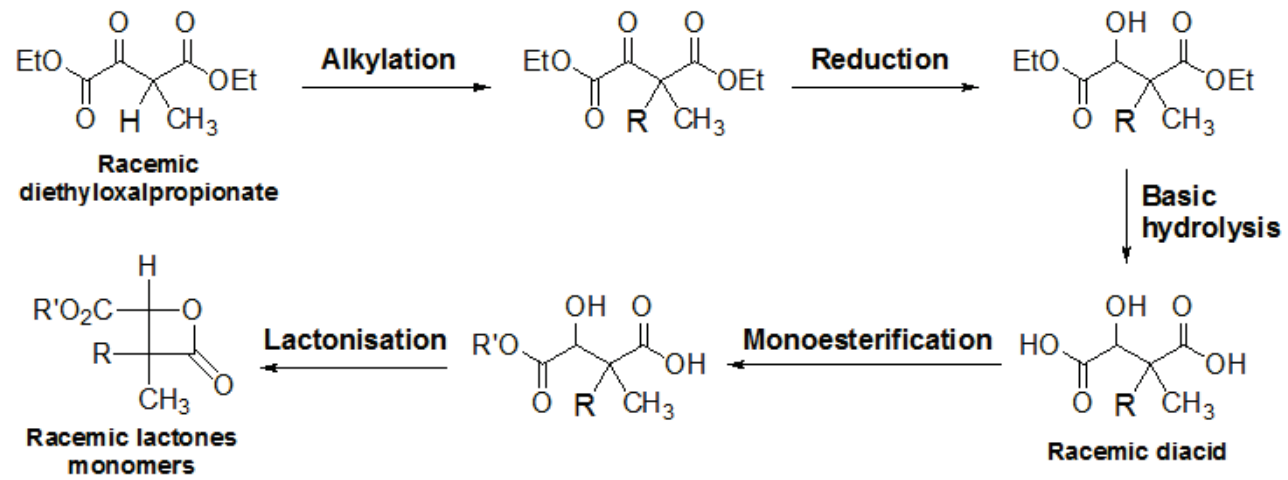

Scheme 2. Synthesis of racemic lactones

Secondly, the synthesis of chiral $\alpha, \alpha^{\prime}, \beta$-trisubstituted $\beta$-lactones has been studied. This new synthesis is realized from commercial L-(S)-malic acid which was then esterified. The resulting diester is alkylated twice and then hydrolyzed under alkaline conditions to provide the chiral acid [89]. The synthesis of various chiral lactones was prepared with the same protocols used in the synthesis of the racemic lactones. These new chiral monomers helped prepare isotactic polyester (Scheme 3) [90].

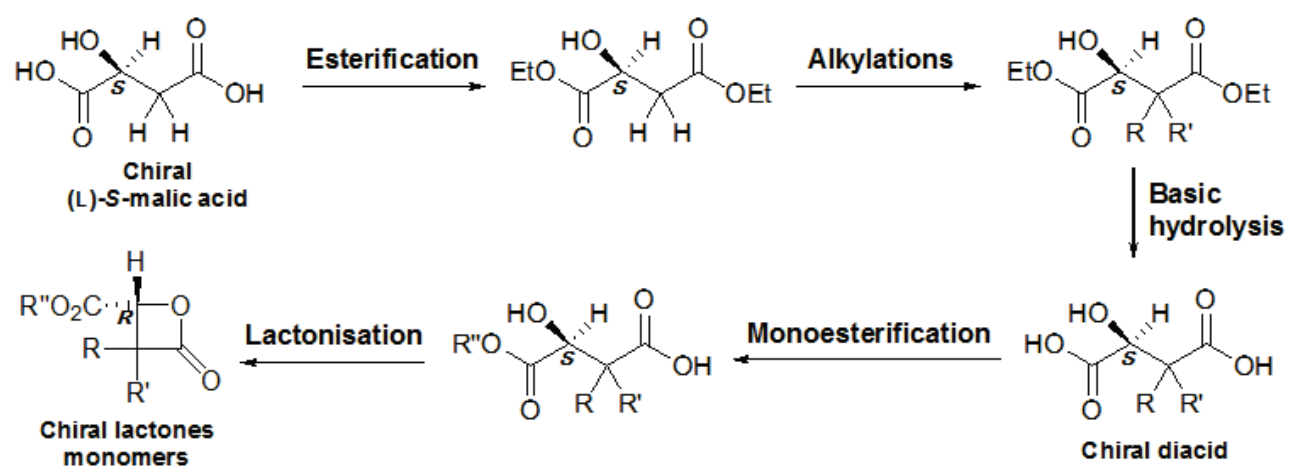

Scheme 3. Synthesis of chiral lactones 
Then, a study has focused on the homopolymerization of two racemic lactones: the benzylic and hexylic lactones. ${ }^{1} \mathrm{H}$ NMR spectroscopic analysis has shown the absence of doublet corresponding to a double bond. In addition, the size exclusion chromatography (SEC) analysis gave a molecular weight value close to the theoretical value and the molecular weight distribution was close to unity. With all of these positive results, it is now possible to conclude that the anionic polymerization allows an excellent control of the molecular weight of polymers [81]. Thirdly, further study was carried out on the block copolymer. In the aim to obtain desired diblock copolymers, a first lactone reacted with the initiator until the band at $1850 \mathrm{~cm}^{-1}$ had disappeared. After complete conversion, a second lactone was added to the solution of polymerization to give the final block copolymer. ${ }^{1} \mathrm{H}$ NMR analysis allowed observing the presence of two blocks with peaks corresponding to two lactones and to calculate the ratio between the two blocs. Differential scanning calorimetry (DSC) gave two distinct Tg values associated with the two blocks, respectively. The SEC measurements showed experimental molecular weights corresponding to the expected ones and narrow molar mass distribution. SEC results had shown an increase of molecular weight between the intermediate block and the final diblock polymer. Several copolymerizations were performed to confirm that the anionic polymerization of these new lactones had a living character [81]. From these very satisfactory results, all searches are now made with polyesters derived PDMMLA. Currently, derivatives PDMMLA are widely studied for different biomedical applications.

\subsection{INTERESTS AND APPLICATION OF PDMMLAS}

The PDMMLA is new and original biodegradable and biocompatible polyester. It has many interests related to its hydrosoluble and bioassimilable characters. It can be custom-synthesized to meet an adequate degradation time. In addition, its structural design was selected to give natural and non-toxic primary products after a complete degradation. Indeed, $(R)$-3,3-dimethylmalic acid which is the final product of hydrolytic degradation of chiral PDMMLA is a natural and non-toxic product involved in the biosynthetic pathway of pantothenate. This metabolite is present in the synthesis of Coenzyme A and gives ketovaline by enzymatic oxidative reaction catalyzed by $\beta, \beta$ -dimethyldehydrogenase (EC.1.1.1.84) [78,80,81,91,92] (Figure 3). 


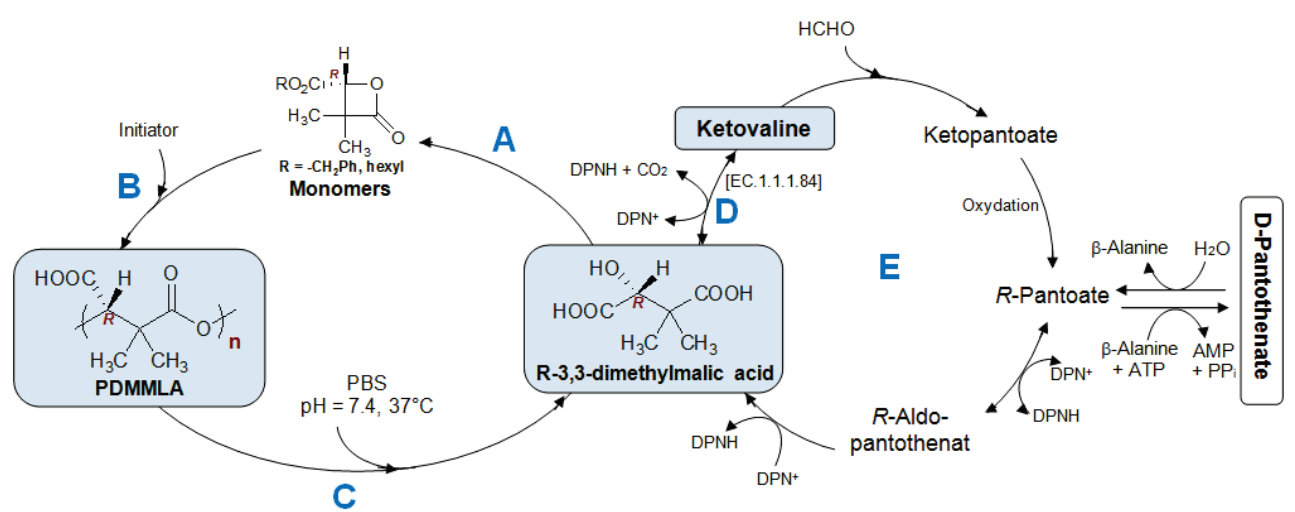

Figure 3. (A) Synthesis of monomers. (B) Synthesis of PDMMLAs with ring-opening polymerization (ROP). (C) PDMMLAs hydrolytic degradation to $(R)$-3,3-dimethylmalic acid. (D) Enzymatic oxidative reaction catalyzed by "EC.1.1.1.84" of $(R)-3,3-$ -dimethylmalic acid to give ketovaline. (E) Degradation cycle of pantothenate [93].

The presence of a chiral center in the repeating unit of PDMMLA provides access to a range of stereocopolymers. This permits the variation of the configurational nature of the polymer and the adjustment of the physicochemical properties of material (crystallinity, solubility, degradability, etc.) depending on the tacticity of the chain.

The PDMMLA has two methyl groups in the $\alpha$-position of the ester function, which increases its hydrophobicity and allows control of molecular weight without transfer reactions relative to PMLA. Moreover, PDMMLA has a side group $R$ incorporated during the polymer synthesis which may be benzylic $(\mathrm{Bn})$, benzyloxypropylic (Bp), or hexylic (He) group. These groups have been selected for two objectives: chemical modifications and adjustment of the hydrophilic/hydrophobic balance and the physicochemical properties of polyesters. Indeed, benzylic and benzyloxypropylic groups are used for their protective role. After a catalytic hydrogenolysis in presence of palladium on charcoal on the polyester, it is possible to obtain, respectively, carboxylic acid and alcohol functions.

However, these ionic and non-charged polyesters will be used on one hand for their hydrophilic properties and on the other hand for allowing chemical modifications and reacting with bioactive or targeting molecules [73,74,94]. Moreover, $-\mathrm{OH}$ functions were often used for their opsonization phenomenon and their excellent blood compatibility and resistance to thrombus formation [54] and carboxylic groups for their favor cell attachment and proliferation. Then, the hexylic group is interesting for its hydrophobic properties which give access to a wide variety of amphiphilic statistical and block copolymers.

These copolyesters may contain a lateral alkyl group or a functional group for coupling and copolymerization of sophisticated groups and bioactive 
molecules. Therewith, it can be able to adduce to the same chain in the lateral position a drug to release lastly during its degradation; we hypothesize that the grafting of the drug can be done during the synthesis of the monomer; it can be attached to the monomer once synthesized or to the polymer after deprotection $[20,95]$.

The PDMMLA and its derivatives may be good candidates for biomedical applications. Different systems can be developed: micelles, nanoparticles, terpolymers, and associative polymers. These new polyesters may be used as macromolecular carriers for gene therapy, for tissue engineering, and for drug delivery. Indeed, PDMMLA derivatives were synthesized and characterized in order to develop a new bioactive coating to cover a coronary stent and deliver a drug to enable the reduction of intrastent restenosis [96-99].

Biocompatibility and adsorption of cell adhesion molecules to the polymer surface (organic polymer medium interface) under suitable conditions (quantity, configuration, flexibility, and accessibility for the receptors involved in cell adhesion) are strongly influenced by different properties. These are the physicochemical properties (roughness, topography, geometry, and surface energy), mechanical performance (rigidity or flexibility), and chemical composition (electric charge, solubility, $\mathrm{pH}$, wettability, and functional groups (amines, carbon unsaturated, $\mathrm{OH},-\mathrm{SO}_{3} \mathrm{H}$, etc.)) of biomaterial surface $[100,101]$.

Similarly, protein adhesion depends on the nature of the surface (hydrophilic and hydrophobic). The cells attach to synthetic surfaces via extracellular matrix adhesive proteins (fibronectin, collagen, vitronectin, laminin, etc.). These proteins which are adsorbed on the surface of biomaterial orient the attachment and the migration of cells on this surface. The control of the chemical composition of the material allows the modulation of its adsorption [102]. The cells have a low affinity for hydrophobic or hydrophilic surfaces. They generally attach to surfaces with a mean value of contact angle (adequate hydrophilic/hydrophobic balance) (Figure 4). 
a

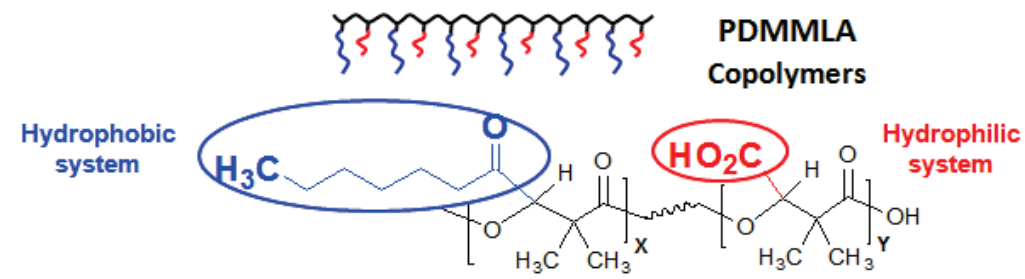

b

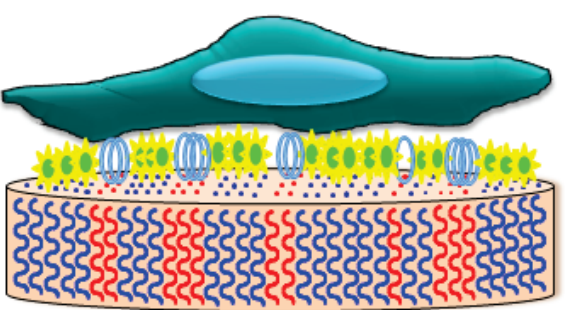

Hydrophobic / Moderately hydrophilic material

Proteins

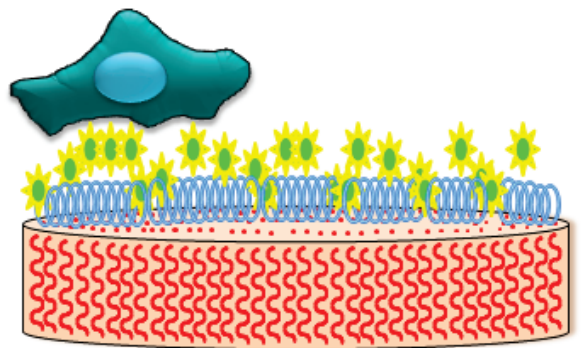

Hydrophilic material

Water molecules

Figure 4. Schematic representation of (a) the copolymer PDMMLA chemical structure and the chain configuration with hydrophilic and hydrophobic parts represented by

the red and blue chains corresponding to carboxylic acid and hexylic groups, respectively, and (b) effect of wettability and surface functional groups on protein adsorption and cell adhesion.

According to the literature, the polymers used as synthetic matrices for the coating of stents and the release of drugs (PGA, PLA, PCL, etc.) $[21,103,104]$ are not perfect solutions. They have a limited diversity of their structures and adverse reactions can be caused by these polymers [105]. It is necessary that the biomaterial used to cover the stent should have good mechanical properties, appropriate surface properties, excellent hemocompatibility, good biocompatibility, and drug delivery capability. That is why recent studies in the literature relate to the possibility of grafting onto the backbone of these polymers of reaction sites to modify their physicochemical and biological characteristics and their degradation rate.

PDMMLA has considerable attention as potential active coating stents thanks to its distinction of being functionalisable to have adjustable properties (hydrophilic/hydrophobic balance, $\mathrm{Tg}$, topography, degradation, cell behavior, etc.) with the requirements of this application and it is achieved with well controlled molecular weight without transfer reactions that occur during the synthesis of PMLA $[93,106,107]$.

In summary, composition, charge, morphology, wettability, and surface free energy of biomaterials must be studied in order to adjust their biological response and protein and cell adhesion. Thus, the surface properties must be 
studied before choosing the favorable drug platform as stent coating. This chapter presents, in the second section, the study of the wettability in static and dynamic conditions, roughness and topography, and surface energy and its components and degradation study of amorphous PDMMLAs.

\subsection{HYDROPHOBIC PDMMLAs}

\subsubsection{Synthesis of hydrophobic PDMMLAs}

PDMMLA can be prepared according to different routes starting from racemic or optically active malic acid [108] or aspartic acid [109] by chemical or biological synthesis routes. Optically active stereocopolymers of malic acid are accessible starting from L- or D-aspartic acid enantiomers [110] or L- or D-malic acid enantiomers [109] as chiral precursors. As mentioned above, a new family of synthetic and isotactic poly $((S)$-3,3-dimethylmalic acid) (chiral PDMMLA) is chemically prepared starting from L-(S)-malic acid.

Chiral PDMMLAs (P1 (benzylic homopolymer), P2 (hexylic homopolymer), P3 (benzyloxypropylic homopolymer), P4 (statistical copolymer 50:50), and P5 (block copolymer 50:50)) were prepared from corresponding chiral $\alpha, \alpha, \beta$ trisubstituted- $\beta$-lactones [90]. To highlight the formation of the various chiral monomers $\alpha, \alpha, \beta$-trisubstituted, a very convenient route in six steps has been realized (Scheme 3) [89]. Indeed, three chiral $\beta$-lactones were prepared for this aim: (4R)-benzyloxycarbonyl-3,3-dimethyl-2-oxetanone (chiral benzylic lactone " $R$ = benzyl"), (4R)-hexyloxycarbonyl-3,3-dimethyl-2-oxetanone (chiral hexylic lactone " $R=$ hexyl"), and (4R)-(3'-benzyloxypropyl)carbonyl-3,3-dimethyl-2-oxetanone (chiral benzyloxypropylic lactone " $R$ = benzyloxypropyl"). These chiral lactones contain one stereogenic center with only $R$ stereochemical configuration. The chiral center of the main chain of homopolymers and copolymers preparing with these lactones has only $S$ stereochemical configuration. With these new chiral $\beta$-lactones in hand, the polymerization of these stereoregular homopolyesters and copolyesters was carried out by living anionic ring-opening polymerization of corresponding monomers using tetraethylammonium benzoate $\left(10^{-2}\right.$ equivalent per mol monomer) as initiator (Scheme 4) [90]. 


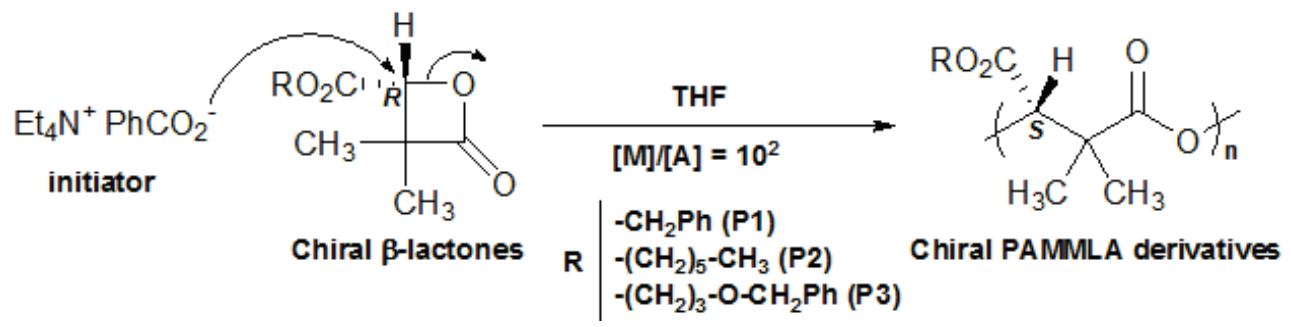

Scheme 4. Anionic ring-opening polymerization of chiral $\alpha, \alpha, \beta$-trisubstituted- $\beta$-lactones

For all polymers, the conversion is complete after approximately $24 \mathrm{~h}$ confirmed with the disappearance of the lactone band at $1834 \mathrm{~cm}^{-1}$ in FTIR spectroscopy analysis (Figure 5). After dissolution in acetone and precipitation in ethanol, high molecular weights with a very good molar mass distribution value (D) close to unity were observed (Table 1) [90].

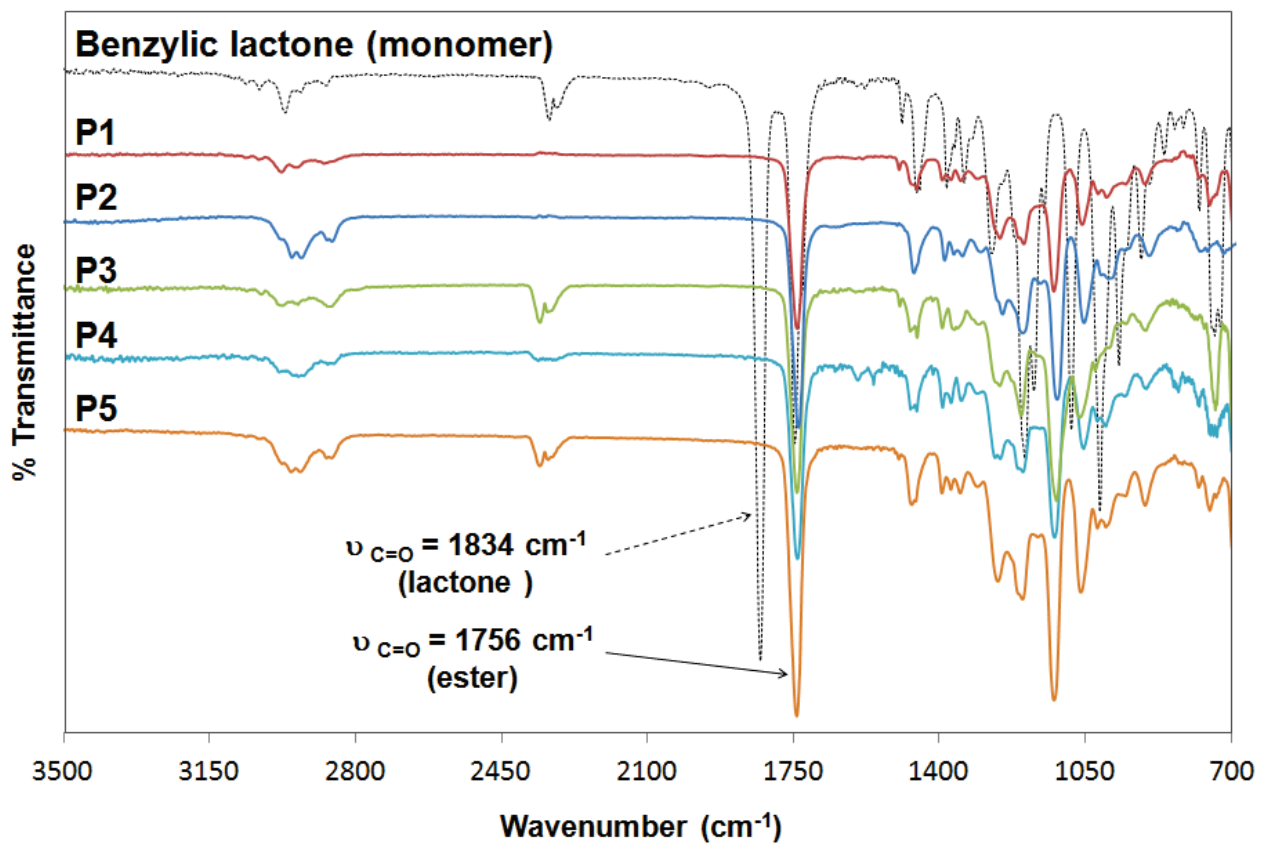

Figure 5. FTIR spectra of chiral benzylic lactone and different chiral PDMMLAs [90]

The chemical structure of different polymers was characterized by ${ }^{1} \mathrm{H}$ and ${ }^{13} \mathrm{C}$ NMR. Indeed, signals around 5.28 and $7.20 \mathrm{ppm}$ on ${ }^{1} \mathrm{H}$ NMR spectrum confirmed the presence of $-\mathrm{CH}_{2}$ benzylic group and those at $0.86,1.26,1.59$, and $4.10 \mathrm{ppm}$ were attributed to hexylic group. In addition, signals assigned to 
benzyloxypropylic group appeared at $1.89,3.49,4.26,4.47$, and $7.29 \mathrm{ppm}$. Moreover, the presence of the lateral chain of benzylic and hexylic ester groups in the ratio 50:50 for statistical and block copolymers (P4 and P5) was confirmed by ${ }^{1} \mathrm{H}$ NMR comparing the peak integrals assigned to the different co-monomers. Indeed, the integration ratio of peak at $4.10 \mathrm{ppm}$ corresponding to $-\mathrm{CH}_{2}-\mathrm{O}-$ hexyl is equivalent to that of $-\mathrm{CH}_{2}-\mathrm{O}-$ benzyl at $5.20 \mathrm{ppm}$ (Figure 6) [90].

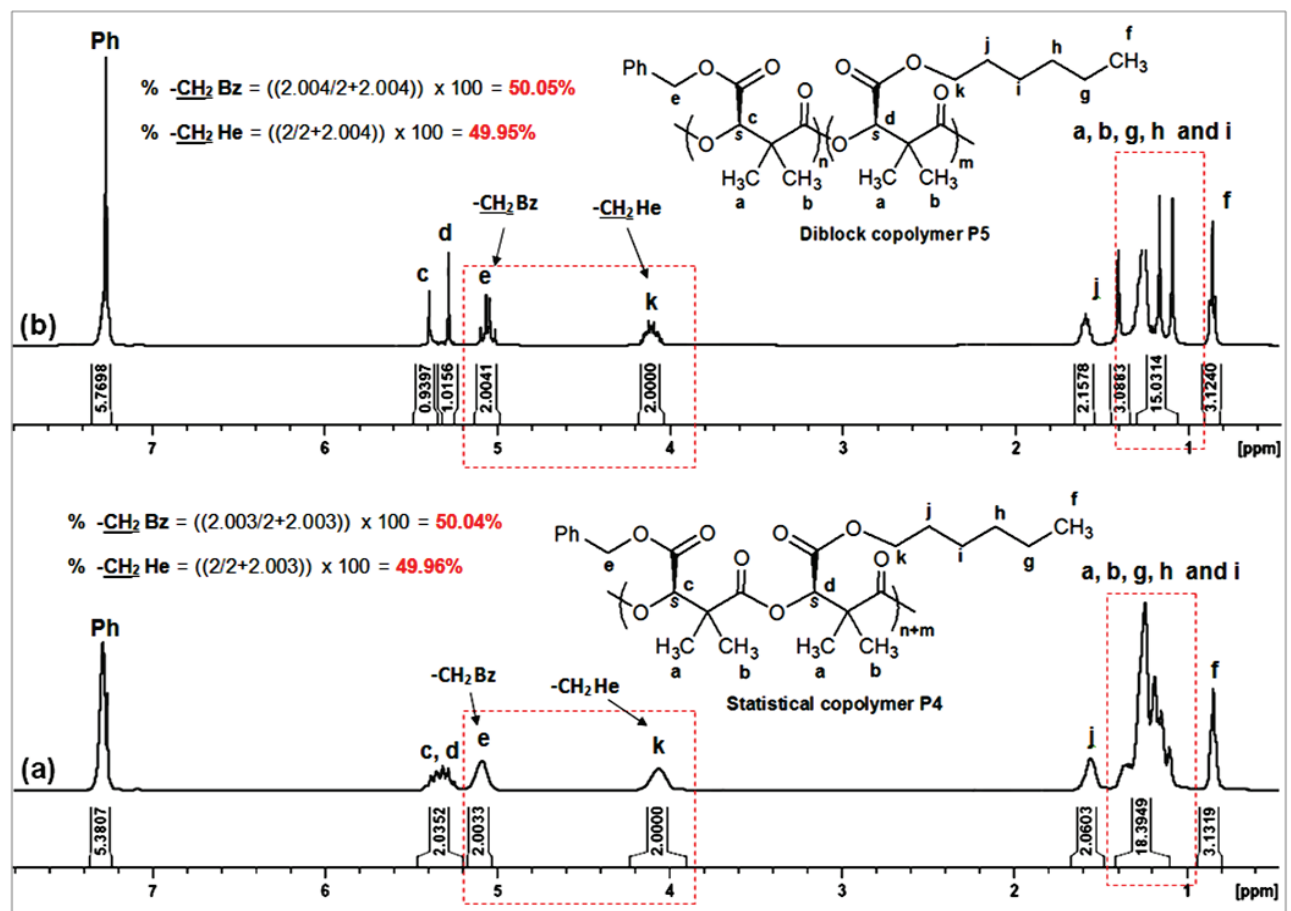

Figure 6. ${ }^{1} \mathrm{H}$ NMR spectra of chiral copolymers: (a) statistical PDMMLA P4 and (b) block PDMMLA P5 [90]

\subsubsection{Physicochemical characterization of hydrophobic PDMMLAs}

Chiral PDMMLAs are characterized by ${ }^{1} \mathrm{H}$ and ${ }^{13} \mathrm{C}$ NMR, SEC, and DSC. All chiral PDMMLAs were compared with the corresponding racemic ones (racemic PDMMLAs (P1' (benzylic homopolymer), P2' (hexylic homopolymer), P3' (benzyloxypropylic homopolymer), P4' (statistical copolymer 50:50), and P5' (block copolymer 50:50)). Table 1 summarizes the obtained results [90]. 
Table 1. Characterization of chiral and racemic homopolymers and copolymers

\begin{tabular}{|c|c|c|c|c|c|c|c|c|c|c|}
\hline & Polym & & $\begin{array}{c}M_{\mathrm{nTh}} \\
\left(\mathrm{g} \mathrm{mol}^{-\mathrm{o}}\right)\end{array}$ & $\begin{array}{c}M_{\mathrm{n}} \\
\left(\mathrm{g} \mathrm{mol}^{-1}\right)^{\mathrm{a}}\end{array}$ & $\begin{array}{c}M_{\mathrm{w}} \\
\left(\mathrm{g} \mathrm{mol}^{-1}\right)^{\mathrm{a}}\end{array}$ & $\mathrm{D}^{\mathrm{a}}$ & $\begin{array}{c}T_{\mathrm{g}} \\
{ }^{\circ} \mathrm{C} \mathrm{C}^{\mathrm{b}}\end{array}$ & $\begin{array}{c}T_{\mathrm{m}} \\
{ }^{\circ} \mathrm{C}^{\mathrm{b}}\end{array}$ & $\begin{array}{c}T_{\mathrm{c}} \\
\left({ }^{\circ} \mathrm{C}\right)^{\mathrm{b}}\end{array}$ & {$[\alpha]^{22} \mathrm{D}\left({ }^{\circ}\right)$} \\
\hline & $\stackrel{\mathscr{c}}{0}$ & P1 & 23400 & 176500 & 177900 & 1.008 & +41.5 & 124.3 & - & -16.6 \\
\hline & $\overrightarrow{2}$ & P2 & 22800 & 111200 & 111700 & 1.004 & -9.1 & 158.2 & - & -47.3 \\
\hline$\varangle$ & $\stackrel{\Xi}{\Xi}$ & P3 & 29200 & 68500 & 70900 & 1.035 & +0.3 & - & 170.9 & +12.8 \\
\hline 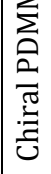 & 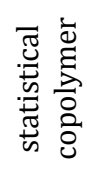 & P4 & 23010 & 233300 & 252700 & 1.083 & +12.2 & - & - & -3.9 \\
\hline & $\begin{array}{l}\frac{\dot{\Xi}}{\mathrm{d}} \\
\text { 응 } \\
\frac{0}{0} \\
\frac{0}{0}\end{array}$ & P5 & 23010 & 164100 & 168300 & 1.025 & $\begin{array}{r}-3.3 \\
+49.2\end{array}$ & 131.8 & - & -22.7 \\
\hline & $\cong$ & P1' & 23400 & 27840 & 29760 & 1.068 & +39.1 & - & - & - \\
\hline & $\frac{5}{0}$ & P2' & 22800 & 19789 & 21283 & 1.075 & -15.0 & - & - & - \\
\hline$\Xi$ & $\underline{\Xi}$ & P3' & 29200 & 25425 & 25757 & 1.013 & -9.0 & - & - & - \\
\hline 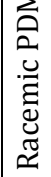 & 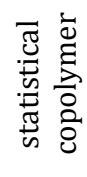 & P4' & 23010 & 23244 & 27811 & 1.196 & +19.3 & - & - & - \\
\hline & 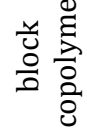 & P5' & 23010 & 19543 & 31105 & 1.591 & $\begin{array}{r}-0.1 \\
+44.2\end{array}$ & - & - & - \\
\hline
\end{tabular}

$M_{\mathrm{nTh}}=$ theoretical $M_{\mathrm{n}}$.

aHPSEC-MALLS-dRI in acetone for racemic PDMMLAs and in THF for chiral PDMMLAs, $0.5 \mathrm{~min}$. bDetermined by DSC, $T_{\mathrm{m}}$ and $T_{\mathrm{c}}$ in the first heating and $T_{\mathrm{g}}$ in the $2^{\text {nd }}$ heating.

\subsubsection{Stereoregularity}

${ }^{13} \mathrm{C}$ NMR spectroscopy was used in the literature to identify the stereoregularity of the polyester [111-114]. The carbonyl peak around $167 \mathrm{ppm}$ is a particularly sensitive and effective signal which provides the 
stereo information [115-117]. In case of observation of three peaks, the racemic polymer is present, indicating atactic fragments in the polymer chain corresponding to isotactic, syndiotactic, and atactic triads. The ratio of the signals indicates the ratio of atactic and isotactic or syndiotactic fragments in the polymer chain. If only a single peak is visible, it can be identified as chiral polymer, representing syndiotactic or isotactic polymer [118]. The isotacticity of stereoregular PDMMLAs was confirmed by comparison with racemic PDMMLAs. Indeed, the carbonyl peak around $167 \mathrm{ppm}$ corresponding to stereopolymers is compared with data obtained from racemic triads [90].

However, for racemic PDMMLA polymers, the carbonyl peak around $167 \mathrm{ppm}$ showed one triplet corresponding to isotactic (i), syndiotactic (s), and atactic triads (a) in the case of racemic homopolymers. In the case of copolymer, only one triplet corresponding to the two units which are undifferentiated (statistical copolymer) and two well-defined triplets corresponding to the two units that presented exactly the same chemical shifts of the two homopolymers (block copolymer) (Figure 7a) [95]. As mentioned in Figure 7b, all stereoregular PDMMLAs showed only one fine peak due to the exclusive iso-sequence [71] corresponding to isotactic triad (i) which has been assigned by comparison with corresponding atactic PDMMLAs presented in Figure 7c [90].

(a)

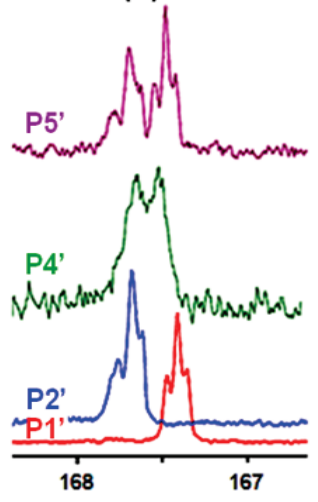

(c)

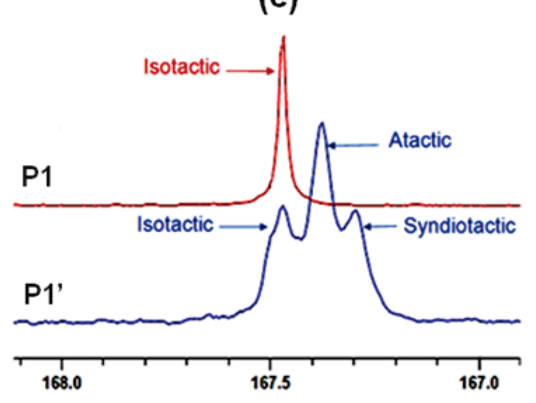

(b)

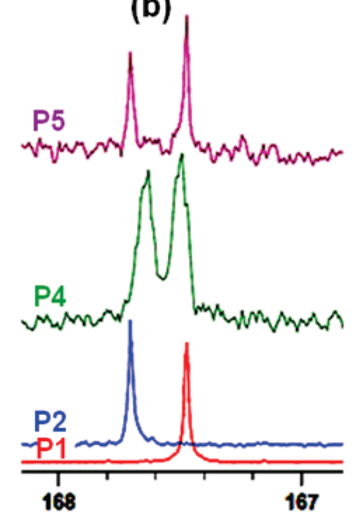

Figure 7. ${ }^{13} \mathrm{C}$ NMR spectra of $\mathrm{C}=0$ signals of lateral ester groups of (a) atactic PDMMLAs (P1', P2', P4', and P5'), (b) isotactic PDMMLAs (P1, P2, P4, and P5), and (c) atactic PDMMLA-Bn P1' and isotactic PDMMLA-Bn P1 showing the distribution of the three triads [90]

Indeed, the chemical shift of the two homopolymers is slightly different. The isotactic triad of hexylic homopolymer P2 (167.70 ppm) is the most deshielded as isotactic triad of benzylic homopolymer P1 (167.47 ppm) that is exactly what has been observed with corresponding atactic homopolymers P2' and P1' (Figure 7). Furthermore, for statistical chiral copolymer P4, we observe the 
presence of two peaks which were not really distinct (167.49 and $167.63 \mathrm{ppm}$ ) because of their distribution in the polymer structure in a random manner. However, chiral block copolyester P5 presents two well-defined peaks (167.47 and $167.70 \mathrm{ppm}$ ) having the same chemical shifts of isotactic homopolymers triads P1 and P2. There are also the same results observed with the corresponding racemic copolymers P4' and P5' (Figure 7) [90].

Table 2 showed different triad percentages of all racemic and chiral PDMMLAs homopolymers. It showed that all chiral homopolymers are $100 \%$ isotactic and that atactic triad of all atactic PDMMLAs homopolymers is mainly formed [90].

Table 2. Attribution of the different triads sequence peaks of different PDMMLAs [90]

\begin{tabular}{|c|c|c|c|c|c|c|c|}
\hline \multirow{2}{*}{} & \multirow{2}{*}{ Polymers } & \multicolumn{3}{|c|}{ Chiral PDMMLAs } & \multicolumn{3}{c|}{ Racemic PDMMLAs } \\
\cline { 2 - 8 } & & P1 & P2 & P3 & P1' $^{\prime}$ & P2' & P3' \\
\hline \multirow{4}{*}{ Triads } & isotactic (\%) & 100 & 100 & 100 & 25 & 27 & 32 \\
\cline { 2 - 8 } & atactic (\%) $^{\mathbf{a}}$ & - & - & - & 53 & 54 & 50 \\
\cline { 2 - 8 } & syndiotactic (\%) & - & - & - & 22 & 19 & 18 \\
\hline
\end{tabular}

aDetermined by ${ }^{13} \mathrm{C}$ NMR.

This relative narrowness of the resonance peaks of chiral PDMMLAs is in favor of the presence of only one stereo-sequence of monomer units. This result confirms also the formation of optically active $\beta$-lactones with $100 \%$ enantiomeric excess. It is already known from the literature that "ring-opening polymerization of poly $[(R)$ or $(S)$-benzyl $\beta$-malate $]$ with configuration inversion of the asymmetric carbon $\mathrm{C}-\mathrm{CO}_{2} \mathrm{R}$ of the $\beta$-lactone without any racemization of this carbon and with the formation of a carboxylate growing chain end" [68] proves the absolute configuration $(S)$ of asymmetric carbon of isotactic polyesters.

\subsubsection{Molecular weights}

Chiral macromolecules organize themselves in crystalline zones and are not isolated, which explains the high molecular weight values obtained in the case of stereoregular PDMMLAs. At the same time, the amorphous and non-stereoregular corresponding PDMMLAs provided a molecular weight that was well correlated with theoretical values indicating the control of the polymerization (Table 1, Figure 8). This observation is consistent with the less solubility of polymer in acetone over time in contrary to amorphous PDMMLAs [90]. 


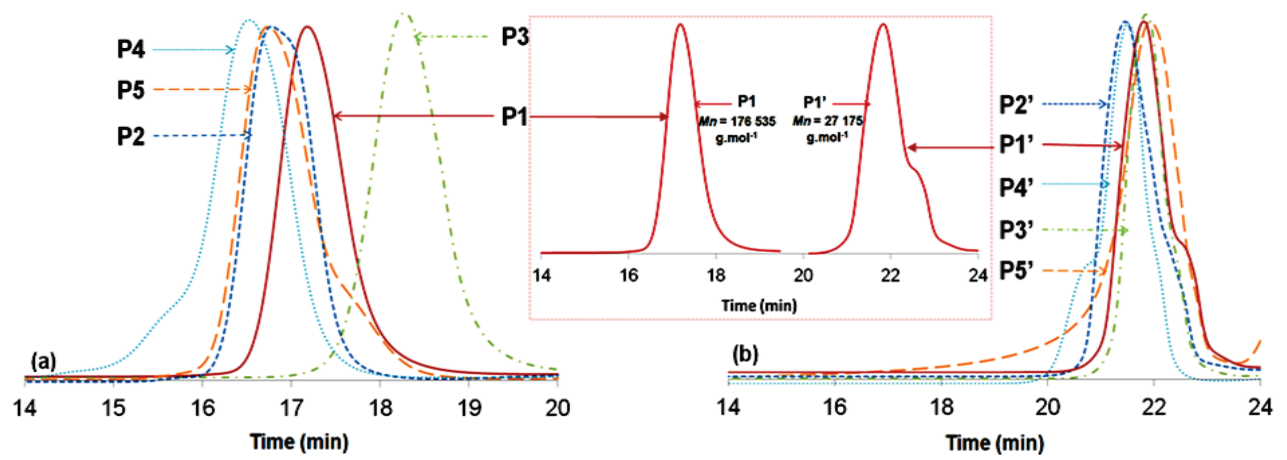

Figure 8. SEC curves of (a) chiral PDMMLAs (P1, P2, P3, P4, and P5) and (b) racemic PDMMLAs (P1', P2', P3', P4', and P5') [90]

\subsubsection{Thermal properties: semi-crystallinity $\left(T_{\mathrm{m}}\right)$, crystallization temperature $\left(T_{\mathrm{c}}\right)$, glass-transition temperature $\left(T_{\mathrm{g}}\right)$, and decomposition temperature $\left(T_{\mathrm{d}}\right)$}

The semi-crystalline PDMMLA homopolymers and copolymers structures were confirmed by DSC which shows a melting temperature $\boldsymbol{T}_{\mathrm{m}}$ observed on all semi-crystalline polyesters (Table 1). The semi-crystalline nature of the networks formed following the copolymerization reaction for P4 and P5 was also supported by X-ray diffraction analysis (XRD). Figure 9 shows the comparison of the DRX obtained profiles of statistical copolymers semicrystalline P4 and amorphous P4' (Figure 9a) and diblock copolymers semicrystalline P5 and amorphous P5' (Figure 9b). XRD patterns confirmed the presence of ordered domains in the macromolecular structure of P4 and P5 with several well-defined peaks which is typical of a semi-crystalline polymer (Figure 9). 

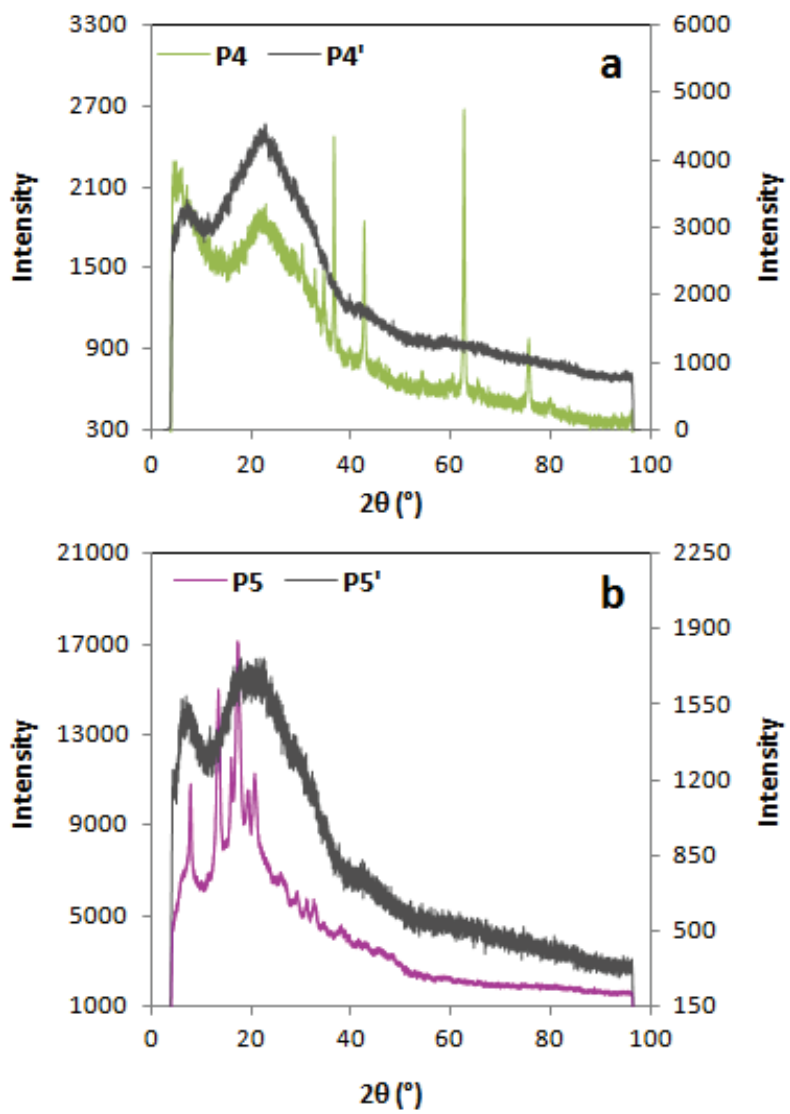

Figure 9. X-ray diffraction patterns for (a) semi-crystalline and amorphous statistical copolymers P4 and P4' and (b) semi-crystalline and amorphous diblock copolymers P5 and P5'

In addition, in the case of chiral homopolyesters, the high glass-transition temperature $\left(T_{\mathrm{g}}\right)$ value for chiral P1 [119] explains the rigidity of aromatic group in the lateral chain of benzylic homopolymer, which causes overrestriction for rotating the substituent along the polymer backbone. On the other hand, owing to flexibility, $\mathbf{P 2}$ shows the lower $T_{\mathrm{g}}$ value consequent to a very decrease in rigidity of polymer sourced from hexylic ester group. Furthermore, diblock copolymer P5 exhibits two $T_{\mathrm{g}}$ values corresponding to hexylic and benzylic units, respectively. However, statistical copolymer P4 (50:50) presents only one logical $T_{\mathrm{g}}$ value distributed between the two $T_{\mathrm{g}}$ values of $\mathbf{P 1}$ and $\mathbf{P 2}$ for a mixture with 50:50 molar ratio of homopolymers. Besides the effect of structure and rigidity of the polymers chains, $T_{\mathrm{g}}$ is affected by their stereochemistry. Indeed, it was observed that all $T_{\mathrm{g}}$ values of amorphous PDMMLAs were lower than corresponding semi-crystalline 
PDMMLAs and $T_{\mathrm{g}}$ increases with higher stereochemistry (Table 1, Figure 10) [90].

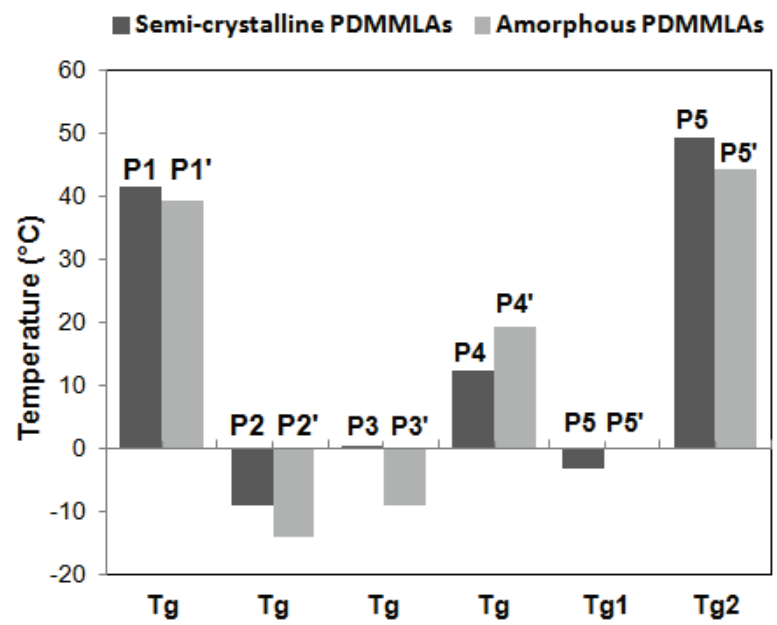

Figure 10. Comparison of $T_{\mathrm{g}}$ values for all chiral PDMMLAs and corresponding racemic PDMMLAs [90]

To further study the thermal stability of these polymers and ensure their use at a temperature range without any degradation, the thermogravimetric analysis (TGA) was carried out to determine the weight loss of different PDMMLAs. TGA was performed under $\mathrm{N}_{2}$ atmosphere at a heating rate of $10^{\circ} \mathrm{C} \mathrm{min}-1$ from room temperature to $700^{\circ} \mathrm{C}$. The weight loss temperatures of $5,50,95$, and $100 \%$ for different PDMMLA were showed in Table 3 [90].

Table 3. Thermal stability of chiral homopolymers and copolymers [90]

\begin{tabular}{|c|c|c|c|c|c|}
\hline \multicolumn{6}{|c|}{$T_{\mathrm{d}}\left({ }^{\circ} \mathrm{C}\right)^{\mathrm{a}}$} \\
\hline \multicolumn{2}{|c|}{ weight loss (\%) } & 5 & 50 & 95 & 100 \\
\hline \multirow{5}{*}{ polymers } & P1 & 258 & 321 & 682 & $>700$ \\
\hline & P2 & 219 & 344 & 368 & 379 \\
\hline & P3 & 250 & 338 & 460 & $\approx 700$ \\
\hline & P4 & 279 & 324 & 421 & 568 \\
\hline & P5 & 286 & 332 & 354 & 510 \\
\hline
\end{tabular}

a Decomposition temperature $\left(T_{\mathrm{d}}\right)$ occurs via TGA.

All studied polymers had homogenous degradation curve. The aromatic group in the lateral chain of homopolymers P1 and P3 leads to degradation in high 
temperature and especially in the case of benzylic homopolymer P1 which is more rigid and less hydrophobic. It contains less carbon number in its side chain in comparison with P3. Therefore, decomposition temperature $\left(T_{\mathrm{d}}\right)$ decreased with increasing of carbon number. Indeed, hexylic homopolymer P2 which contains in its lateral chain a group of a linear chain of six carbons had the very low $T_{\mathrm{d}}$ values over the degradation. This phenomenon can be attributed to the flexibility of this hexylic group. However, $T_{\mathrm{d}}$ was sharply increased above $300^{\circ} \mathrm{C}$ for all of these polymers indicating the beginning of their decomposition. P1 presented the highest value of $T_{\mathrm{d}}$ and a very slight weight loss. Indeed, it decomposed completely at $T_{\mathrm{d}}$ above to $700{ }^{\circ} \mathrm{C}$ whereas P2 had the lowest value and lost total weight at $379^{\circ} \mathrm{C}$. $T_{\mathrm{d}}$ of $\mathbf{P 3}$ was between those of $\mathbf{P 1}$ and $\mathbf{P 2}$ and lost almost total weight at $700{ }^{\circ} \mathrm{C}$ (Table 3) [90].

In addition, the TGA curve of statistical PDMMLA P4 (50:50) and block copolymer PDMMLA P5 (50:50) was studied. Their thermal stability was found between those of the corresponding homopolymers P1 and P2 apart at initial $T_{\mathrm{d}}$ which was slightly higher. Thus, at a weight loss of $100 \%, T_{\mathrm{d}}$ value of P4 and P5 was an almost average between the two corresponding homopolymers values (calculated: $536^{\circ} \mathrm{C}$ ). This indicated also that the two components were ideally mixed in these copolymer systems. Finally, these results show that $T_{\mathrm{m}}, T_{\mathrm{g}}$, and $T_{\mathrm{d}}$ values (at weight loss of $50 \%$ ) of P1 and P2 and their copolymers P4 and P5 presented linearity as a function on their compositions $\left(R^{2}=0.906,0.991\right.$, and 0.999 , resp.) which confirmed the ideal mixing of the copolymer system (Figure 11) [90].

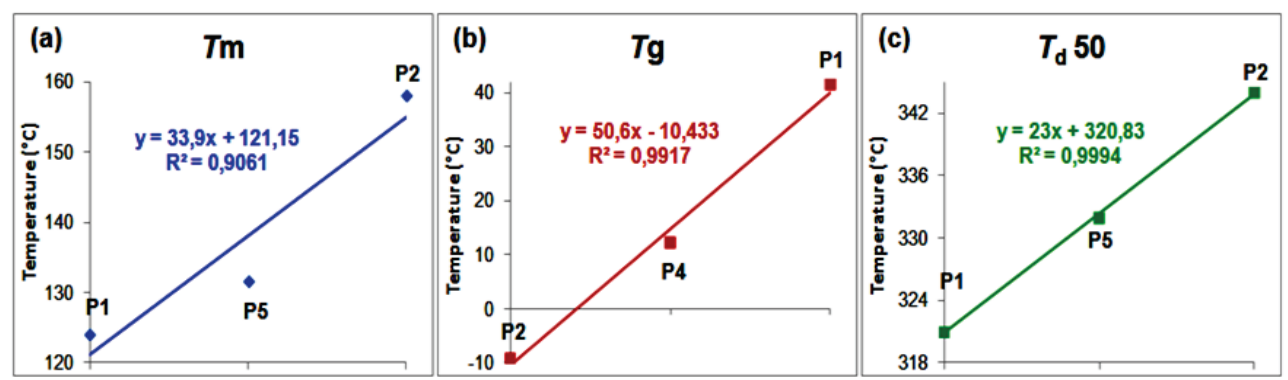

Figure 11. Linear relation between "polymers compositions (homopolymers (P1 and P2) and their copolymers 50:50 (P4 and P5)" and "(a) $\boldsymbol{T}_{\mathrm{m}}$, (b) $\boldsymbol{T}_{\mathrm{g}}$, and (c) $T_{\mathrm{d}}$ at weight loss of $50 \%$."

These polymers present a high thermal stability. Therefore, the present study showed that thermo-mechanical properties such as crystallinity, melting point, or stereo-polymers rigidity/flexibility of these materials depend on their structure design and stereochemistry. These properties can be easily adjusted by varying the ratio of monomers also that choose the statistical or block copolymerization [120-123], underlining the above results. 


\subsection{HYDROPHILIC/HYDROPHOBIC PDMMLAs}

\subsubsection{Synthesis and chemical characterization of hydrophilic/hydrophobic PDMMLAs}

Synthetic amorphous PDMMLAs homopolymers P1', P2', and P3' were prepared by a living anionic ring-opening polymerization of corresponding racemic $\beta$-lactones as monomers: benzylic lactone (4-benzyloxycarbonyl-3,3-dimethyl-2-oxetanone) " $R=-\mathrm{CH}_{2} \mathrm{Ph}^{\prime} \quad(\mathrm{Bn})$, hexylic lactone (4-hexyloxycarbonyl-3,3-dimethyl-2-oxetanone) " $R=-\left(\mathrm{CH}_{2}\right)_{5}-\mathrm{CH}_{3}$ " (He), and benzyloxypropylic lactone (4-(3-benzyloxypropyl)carbonyl-3,3-dimethyl-2-oxetanone) " $\mathrm{R}=-\left(\mathrm{CH}_{2}\right)_{3}-\mathrm{O}-\mathrm{CH}_{2} \mathrm{Ph}$," respectively, in anhydrous THF solution using tetraethylammonium benzoate as initiator (Scheme 5) [95]. These racemic $\beta$-lactones monomers were synthesized according to the literature procedure as well [81]. P1' and P3' were used for the synthesis of corresponding homopolymers, PDMMLA-COOH, and PDMMLA-OH, respectively. Then, three statistical copolymers with different hydrophobic/hydrophilic balance in the side chain of copolymers were also prepared from two different racemic $\beta$-lactones (benzylic and hexylic lactones): PDMMLA-COOH $10-\mathrm{Co}-\mathrm{He}_{90}$ named 10/90, PDMMLA-COOH $20-\mathrm{Co}$ $-\mathrm{He}_{80}$ named 20/80, and PDMMLA-COOH $30-\mathrm{Co}-\mathrm{He}_{70}$ named 30/70.

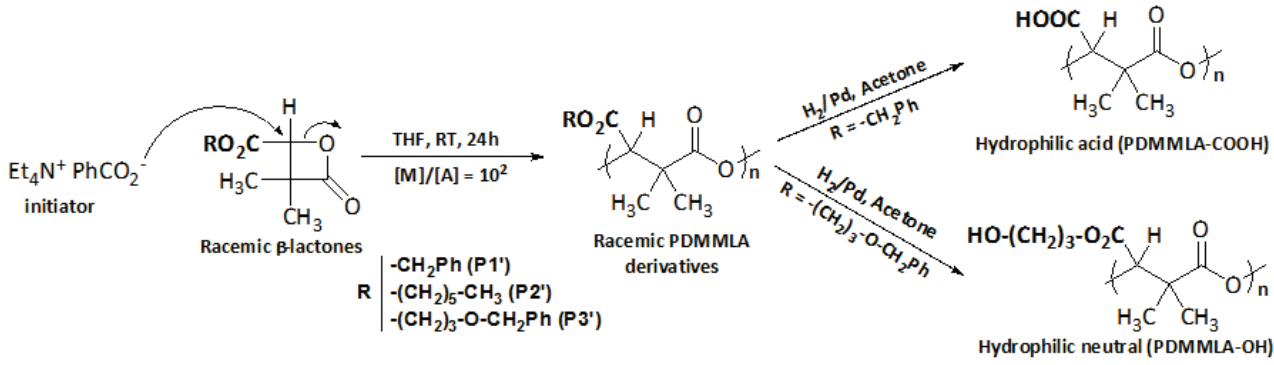

Scheme 5. Synthetic route of amorphous PDMMLA derivatives

The polymerization was followed by FTIR spectroscopy analysis which showed the ester characteristic band at $1751 \mathrm{~cm}^{-1}$ and the disappearance of the lactone band at $1838 \mathrm{~cm}^{-1}$ for all polymers. The chemical structure of different polymers was characterized by ${ }^{1} \mathrm{H}$ and ${ }^{13} \mathrm{C}$ NMR. Therefore, signals around 5.20 and $7.38 \mathrm{ppm}$ on ${ }^{1} \mathrm{H}$ NMR spectrum confirmed the presence of benzylic group and those around $0.89,1.26$, and $4.10 \mathrm{ppm}$ characterized the hexylic group. In addition, signals assigned to benzyloxypropylic group appeared at 1.93, 3.54, 4.27, and 4.49 ppm [106].

The co-monomers relative contents $(10,20$, and $30 \%)$ were obtained by ${ }^{1} \mathrm{H}$ NMR using the integration ratio of peak at 4.15 ppm corresponding to $-\mathrm{CH}_{2}-\mathrm{O}-$ 
hexyl and that at $5.20 \mathrm{ppm}$ corresponding to $-\mathrm{CH}_{2}-\mathrm{O}$ - benzyl (Figure 12). After a catalytic hydrogenolysis in presence of $10 \%$ of palladium on charcoal on the polyester, it is possible to obtain carboxylic acid group (when $R=-\mathrm{CH}_{2} \mathrm{Ph}$ ) and alcohol group (when $R=-\left(\mathrm{CH}_{2}\right)_{3}-\mathrm{O}-\mathrm{CH}_{2} \mathrm{Ph}$ ) (Scheme 5). As mentioned above, these ionic and non-charged groups (carboxylic acid and alcohol, resp.) are used on one hand for their hydrophilic properties and on the other hand for the possibility to react with bioactive or targeting molecules [73,74,94]. The hexylic group is used for its hydrophobic properties, which gives access to a wide variety of amphiphilic copolymers. Polymers catalytic hydrogenolysis was confirmed by the disappearance of benzylic peaks at 5.2 and $7.4 \mathrm{ppm}$ on ${ }^{1} \mathrm{H}$ NMR spectrum for PDMMLA-COOH, PDMMLA-OH, and copolymers (Figure 12) [106].

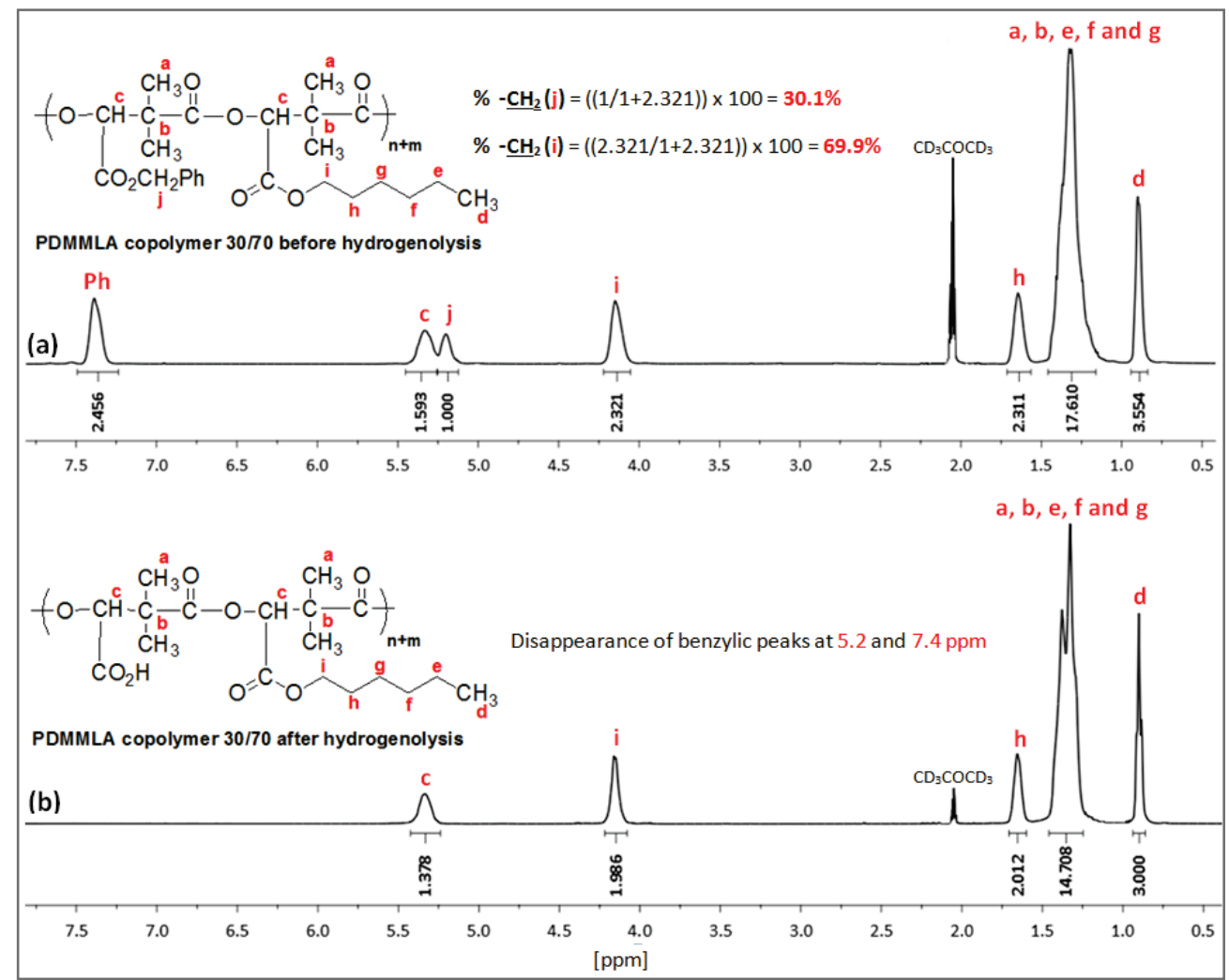

Figure 12. ${ }^{1} \mathrm{H}$ NMR spectra of copolymers 30/70 (a) before hydrogenolysis (PDMMLA$-\mathrm{Bn}_{30}-\mathrm{Co}-\mathrm{He}_{70}$ ) and (b) after hydrogenolysis (PDMMLA-COOH $\mathrm{H}_{30}-\mathrm{CO}-\mathrm{He}_{70}$ ) [106] 


\subsubsection{Physicochemical properties and surface characterization of PDMMLAs}

The ideal biomaterial for vascular applications must provide thermomechanical properties, good biocompatibility, and cell response (adhesion, morphology, attachment, behavior, proliferation, and migration of cells). Indeed, the surface properties of biomaterials (roughness and morphology, chemical composition, charge, wettability, and surface energy) are the main factor that affects the biological response (immediate and longterm response) between the biomaterial and the vascular tissue and blood $[100,101]$. According to literature, the surface energy is the most important factor in determining the thrombogenicity in blood. The affinity of the polymer surface with water increases with increasing surface energy and therefore the increase of thrombogenicity in the blood medium [124].

Another very important factor is the surface roughness. The thrombogenicity increases on rougher surfaces. This is due to the higher blood protein adsorption, activation, and aggregation of platelet [124]. Thus, a stent coating should have good interaction with blood, be incorporated by the vascular tissue, and presents the advantage to minimize the inflammatory response. This is thanks to its good surface properties.

\subsubsection{Thermal properties}

All PDMMLAs present good thermal and surface properties (low $T_{\mathrm{g}}$ and surface energy and functional hydrophilic molecules on its chain which adjusts their properties and interactions with body tissue). This is precisely meeting the requirements of the intended cardiovascular applications. Indeed, the absolute average molecular weights and molecular weight distributions of all studied PDMMLAs are summarized in Table 4. $T_{\mathrm{g}}$ of PDMMLA copolymers do not exceed $20^{\circ} \mathrm{C}\left(-15,+8.2\right.$, and $+20^{\circ} \mathrm{C}$ for $10 / 90,20 / 80$, and $30 / 70$, resp. $)$ which is lower than the physiological temperature whereas PLA has higher $T_{\mathrm{g}}$ (about $63{ }^{\circ} \mathrm{C}$ ), having thus less ductility and softness. It was found that the rigidity of the polymer chains decreased with the decrease of the carboxylic acidic groups. In summary, as a comparison between the PDMMLAs amorphous copolymers, 10/90 was the most flexible and 30/70 the most rigid. 20/80 had the average value. This means that they have viscoelastic character and flexible chains which can be modulated with varying hydrophilic/hydrophobic balance. These thermal properties of PDMMLA polymers present an encouraging result for applying these biomaterials for cardiovascular applications. 
Table 4. Characterization of different homopolymers and copolymers (PDMMLA-COOH ${ }_{x}-\mathrm{Co}-\mathrm{He}_{y}$ )

\begin{tabular}{|c|c|c|c|c|c|c|c|}
\hline \multirow{2}{*}{\multicolumn{3}{|c|}{ Polymers }} & \multicolumn{5}{|c|}{ Characterization of polyesters } \\
\hline & & & \multirow{2}{*}{$\begin{array}{c}\begin{array}{c}M_{\mathrm{nTh}} \\
\left(\mathrm{g} \mathrm{mol}^{-\mathrm{o}}\right)\end{array} \\
23400\end{array}$} & \multirow{2}{*}{$\begin{array}{c}\begin{array}{c}M_{\mathrm{n}} \\
\left(\mathrm{g} \mathrm{mol}^{-\mathrm{o}}\right)^{(\mathrm{a})}\end{array} \\
19789\end{array}$} & \multirow{2}{*}{$\begin{array}{c}\begin{array}{c}M_{\mathrm{w}} \\
\left(\mathrm{g} \mathrm{mol}^{-\mathrm{o}}\right)^{(\mathrm{a})}\end{array} \\
21283\end{array}$} & \multirow{2}{*}{$\begin{array}{l}\mathrm{D}^{(\mathrm{a})} \\
1.07\end{array}$} & \multirow{2}{*}{$\begin{array}{c}\begin{array}{c}T_{\mathrm{g}} \\
\left(\mathrm{C}^{\circ}\right)^{(\mathrm{b})}\end{array} \\
-15.0\end{array}$} \\
\hline \multirow{3}{*}{\multicolumn{2}{|c|}{ 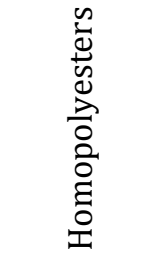 }} & P2' & & & & & \\
\hline & & $\begin{array}{c}\text { PDMMLA- } \\
\mathrm{COOH}\end{array}$ & 22800 & 29393 & 30120 & 1.02 & +67.9 \\
\hline & & PDMMLA-OH & 29200 & 19955 & 20842 & 1.04 & +7.6 \\
\hline \multirow{3}{*}{ 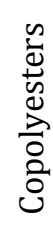 } & \multirow{3}{*}{ 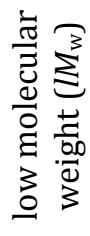 } & $10 / 90$ & 22860 & 18062 & 19109 & 1.05 & -14.2 \\
\hline & & $20 / 80$ & 22920 & 18293 & 20015 & 1.09 & +8.2 \\
\hline & & $30 / 70$ & 22980 & 18549 & 20776 & 1.12 & +20.0 \\
\hline \multirow{3}{*}{ 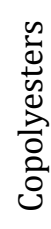 } & \multirow{3}{*}{ 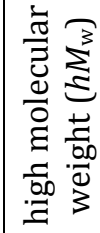 } & $10 / 90$ & 228600 & 148060 & 153800 & 1,04 & ND \\
\hline & & $20 / 80$ & 229200 & 214420 & 231800 & 1,08 & ND \\
\hline & & $30 / 70$ & 229800 & 354460 & 364800 & 1,03 & ND \\
\hline
\end{tabular}

$M_{\mathrm{nTh}}=$ theoretical $M_{\mathrm{n}}$.

(a)HPSEC-MALLS-dRI in THF, $0.5 \mathrm{~min}$.

(b)Determined by DSC.

ND: not determined.

\subsubsection{Surfaces roughness and topography}

The roughness and topography of PDMMLA surfaces are determined via atomic force microscope (AFM) (Figure 13). All PDMMLAs presented a smooth and flat surface (root mean squared roughness $R a<1.2 \mathrm{~nm}$ ) [106]. The wettability of the surface is affected, on one hand, by the chemical heterogeneity of the material and, on the other hand, by the surface roughness. This result shows that the surface wettability of PDMMLAs is not affected by the surface roughness $(R a<0.1 \mu \mathrm{m})[125]$. 


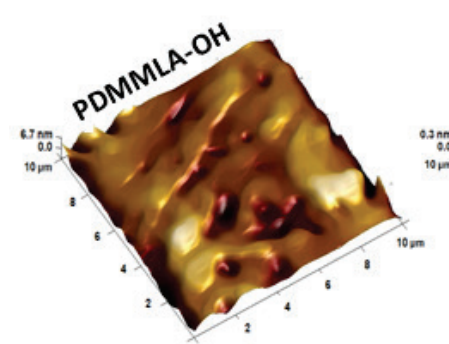

$\mathrm{Ra}: 1.11 \mathrm{~nm}$

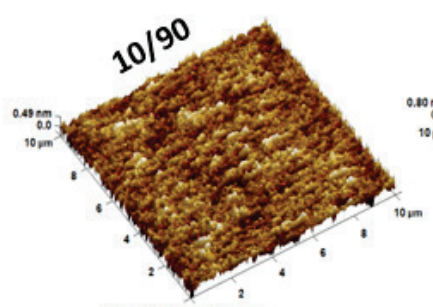

$\mathrm{Ra}: 0.10 \mathrm{~nm}$

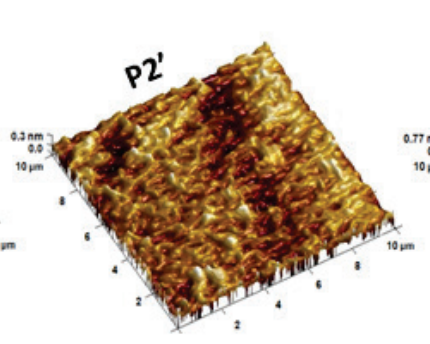

$\mathrm{Ra}: 0.05 \mathrm{~nm}$

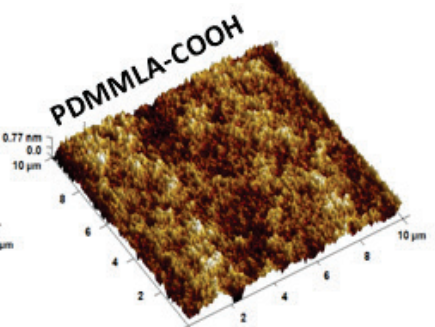

$\mathrm{Ra}: 0.16 \mathrm{~nm}$

Figure 13. 3D AFM images and average roughness $R a(\mathrm{~nm})$ of all amorphous PDMMLAs [106]

\subsubsection{Surfaces wettability and water sorption/desorption}

The wettability of the different PDMMLA derivatives surfaces was characterized in static and dynamic conditions. Figure 14 shows contact angles for the different surfaces obtained, respectively, by sessile drop method (static angle $\left(\theta_{\mathrm{S}}\right)$ ) and tensiometry (dynamic contact angles) at cycle $1\left(\theta_{\mathrm{A}}^{1}\right)$ and cycle $10\left(\theta_{\AA}^{10}\right)$ and average between the 10 cycles $\left(\theta_{\mathrm{av}}\right)$. Angle at cycle 1 is always superior to angle at cycle 10 . The difference is increasing with percentage of acidity (\% A). This is due to hydratation of surfaces polar groups (hydrogen bonding) during cycling, leading to a decrease of advancing contact angle values. Average angle is close to that of sessile drop angle for the three copolymers $[106,107]$. 


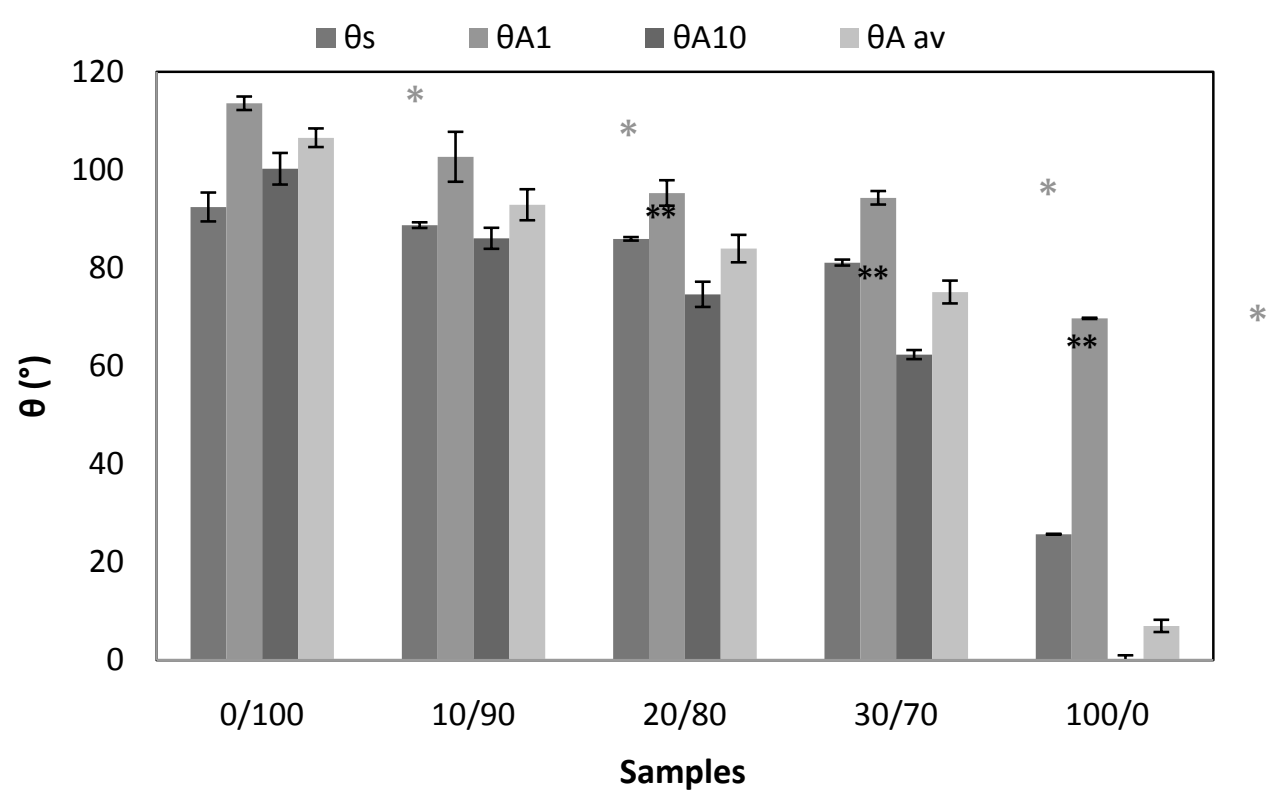

Figure 14. Contact angles for the different PDMMLA surfaces obtained by sessile drop method (static angle $\left(\theta_{\mathrm{s}}\right)$ ) and tensiometry (dynamic contact angles) at cycle $1\left(\theta_{\mathrm{A}}^{1}\right)$ and cycle $10\left(\theta_{\mathrm{A}}^{10}\right)$ and average between the 10 cycles $\left(\theta_{\mathrm{av}}\right)(n=3, * p<0.01$, $* * p<0.0001$ ) [106,107].

For P2' $(0 / 100)$ homopolymer, average angle is greater than that of sessile drop. This is the reverse for PDMMLA-COOH (100/0). Whatever the method, angles are decreasing with \% A. Cycle 1 contact angle is always higher than the other angles in particular sessile drop. Cycle 10 is always the lowest, except for P2' surface. Tensiometry is more sensitive to chemical heterogeneity than sessile drop method because, statistically, some drops can be deposited on homogeneous areas, depending on the scale of the heterogeneity surface distribution. This is due to the fact that tensiometry integrates the overall both sides of surface whereas sessile drop probes only few localized points of the global surface.

Heterogeneous samples in this study are all exhibiting more than $70 \%$ of hydrophobicity and so surface hydrophilicity is represented by less than $30 \%$ in surface distribution. The probability for a drop to probe these hydrophilic areas is less than $30 \%$. The accuracy of sessile drop method is thus very low compared to that of tensiometry. P2' surface, totally hydrophobic, is the only one with a cycle 10 angle higher than for sessile drop. This is in agreement with the reverse observation for PDMMLA-COOH surface with a cycle 10 angle reduced to zero and lower than sessile drop angle. These results were also confirmed by statistical analysis which revealed sensitivity higher at cycle 10 than cycle 1 for each sample [107]. 
In summary, beyond the first cycle, the sample surface has changed, due to interaction with water. A hydrophobic surface has less interaction with water than a hydrophilic surface. This difference is due to the penetration of water to the interior of the polymer chains forming hydrogen interactions with hydrophilic surfaces, partially and irreversibly at the first cycle. Then, the liquid spreads from cycle to another to form a water film distributed now over the entire surface of the polymer. This action causes the polymer chains mobility and the molecular reorientation which reveal all hydrophilic functions on the surface and therefore the hydrophobic functions inside the film (Figure 15) [126]. This phenomenon increases with increasing of \% A. It was previously confirmed with the acute increase of the hysteresis value of the most hydrophilic surface PDMMLA-COOH [107].

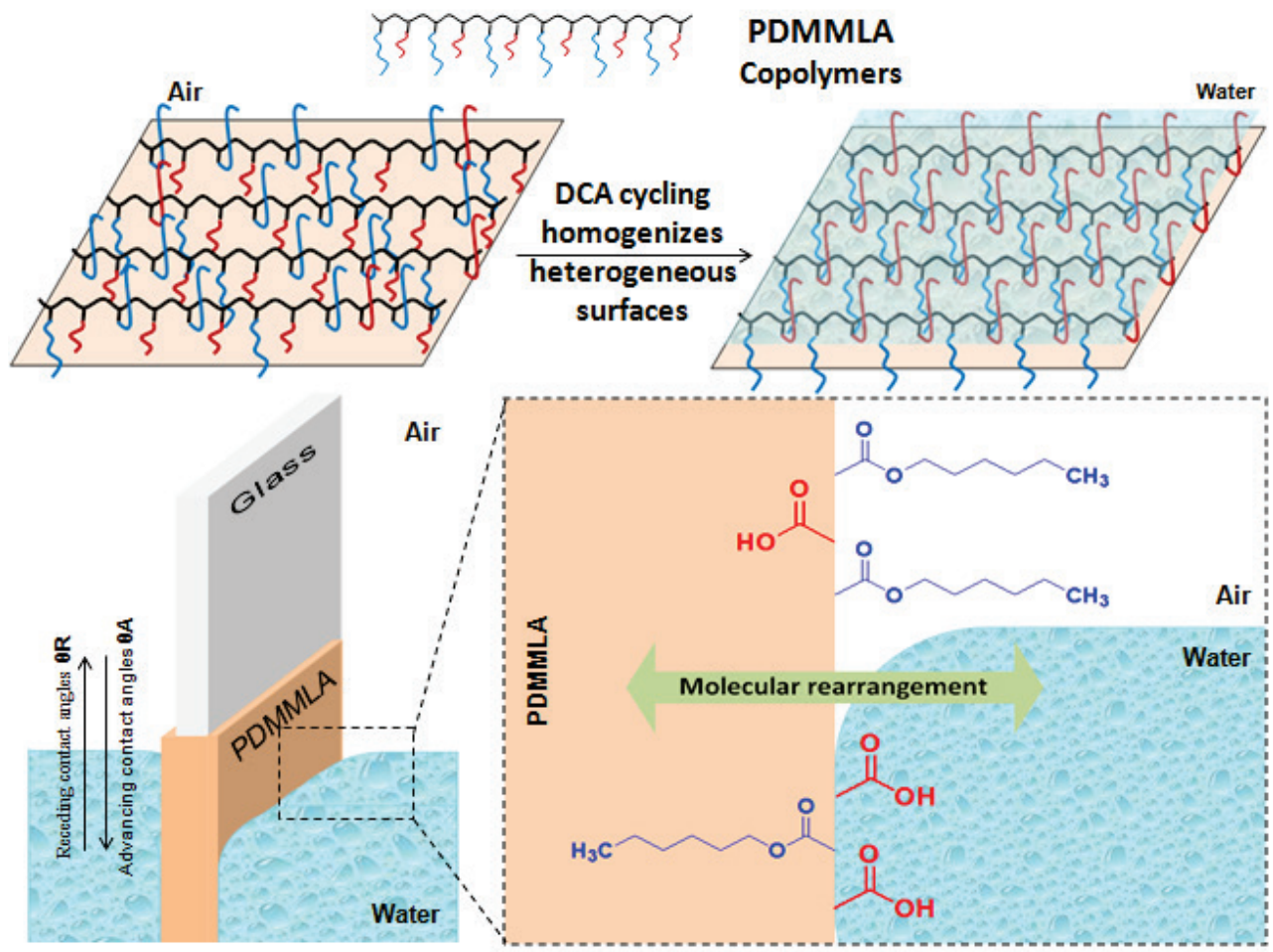

Figure 15. Schematic representation of PDMMLA copolymer film deposited on glass slides during the tensiometric immersion in water, the preferential orientation of copolymer side chains, and the molecular reorganization and the homogenization of the copolymer surface after dynamic contact angle (DCA) cycling [107]

Additionally, during the immersion/emersion measurement, the polymer film can absorb and desorb water. Therefore, the phenomenon of water sorption/desorption was also studied in this work. For this experiment, only 
3 cycles were performed because the evolution of advancing angles during cycling after cycle 2 was found to be not significant [107]. All films had a lower water uptake than $6 \%$ in the studied conditions of measurement (Figure 16). Because all relationships between hydrophilicity and \% A exhibited good R2 values in the above data (for advancing angles), one can consider that these low values had a negligible effect on the evolution of hydrophilicity of the film surfaces during cycling [107].

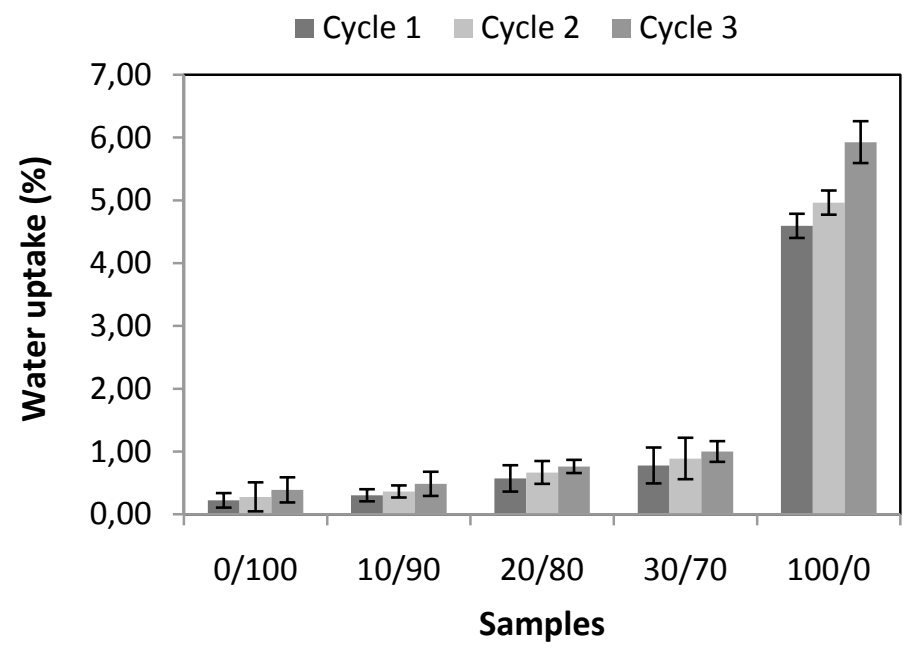

Figure 16. Water uptake of different PDMMLAs films [107]

\subsubsection{Surfaces free energy and its components}

Besides, the total surface free energy ( $\gamma_{\text {Tот }}$ ) for each surface is presented in Table 5 [106]. Its value clearly increases with \% A. It also indicates the values of dispersive $\left(\gamma_{\mathrm{LW}}\right)$ and polar acid-base component $\left(\gamma_{\mathrm{AB}}\right)$ of the surface free energy. Polar interactions are due to Coulomb interactions between permanent dipoles but also to interactions between induced and permanent ones whereas time fluctuations in the molecules charge distribution contribute to dispersive interactions [127]. For all the surfaces $\gamma_{\mathrm{LW}}$ is higher than $\gamma_{\mathrm{AB}}$ due to the major presence of $-\mathrm{CH}_{2}$ groups inside the polymer chains. However $\gamma_{\mathrm{AB}}$ is not negligible and is increasing regularly with \% $\mathrm{A}$ which brings polar oxygen atoms in the structure. This correlation includes not only the chemically heterogeneous copolymers $(10 / 90,20 / 80$, and $30 / 70)$ but also the two homogeneous references $(0 / 100$ and 100/0) [106]. 
Table 5. Values and standard deviations of total surface free energy $\left(\gamma_{\text {Tот }}\right)$, dispersive $\left(\gamma_{\mathrm{LW}}\right)$, polar acid-base $\left(\gamma_{\mathrm{AB}}\right)$, acidic $\left(\gamma_{\mathrm{A}}\right)$, and basic $\left(\gamma_{\mathrm{B}}\right)$ components of surface energy, for each surface [106].

\begin{tabular}{|c|c|c|c|c|c|}
\hline \multirow{2}{*}{ Samples } & \multicolumn{5}{|c|}{ Surface free energy and its components $\left(\mathrm{mJ} \mathrm{m}^{-2}\right)$} \\
\cline { 2 - 6 } & $\gamma_{\text {Tот }}$ & $\gamma_{\mathrm{LW}}$ & $\gamma_{\mathrm{AB}}$ & $\gamma_{\mathrm{A}}$ & $\gamma_{\mathrm{B}}$ \\
\hline P2' 0/100 & $39,13 \pm 0,01$ & $38,89 \pm 0,01$ & $0,24 \pm 0,01$ & $1,48 \pm 0,13$ & $0,01 \pm 0,01$ \\
\hline $10 / 90$ & $41,21 \pm 0,07$ & $38,22 \pm 0,01$ & $3,01 \pm 0,08$ & $5,35 \pm 0,22$ & $0,44 \pm 0,04$ \\
\hline $20 / 80$ & $44,19 \pm 0,21$ & $36,86 \pm 0,21$ & $7,32 \pm 0,18$ & $10,5 \pm 0,22$ & $1,28 \pm 0,06$ \\
\hline $30 / 70$ & $47,5 \pm 0,32$ & $35,79 \pm 0,01$ & $11,59 \pm 0,14$ & $17,59 \pm 0,78$ & $1,94 \pm 0,01$ \\
\hline $\begin{array}{c}\text { PDMMLA- } \\
-\mathrm{COOH} \\
100 / 0\end{array}$ & $54,16 \pm 0,6$ & $32,5 \pm 0,85$ & $21,66 \pm 1,45$ & $46,87 \pm 0,53$ & $2,51 \pm 0,31$ \\
\hline
\end{tabular}

It is important to quantify polar acid-base and/or apolar surface energy components with accuracy for a better understanding of cell behavior in contact with a biomaterial [128]. Indeed, water contact angle and total surface free energy are generally not sufficient parameters to explain differences in cell response. In contrast, acidic or basic surface energy components can be parameters but enable us to discriminate between biomaterial surfaces [128]. Moreover, an analysis of protein adsorption onto the surfaces of interest could help to go further in the understanding of the correlations between material surface chemistry and biocompatibility. For example, DCA could detect particular protein adsorption behavior depending on the biomaterial surface chemistry as it has been shown for polysaccharides polyelectrolytes films [129].

\subsubsection{In vitro biodegradation rate and nature of PDMMLAs and the cytotoxicity of degradation products}

Drug Eluting Stents (DESs) based on biodegradable polymers should be degraded in a few months preventing the risk of thrombosis. PDMMLA is custom-synthesized to meet an adequate degradation time. The hydrolytic degradation study of PDMMLAs was performed under physiological conditions for a 6-month period. The most important factors that influence the kinetic degradation of polymers (molecular weight, nature and stability of functional groups, charge, natural biological enzymes, $\mathrm{pH}$, and temperature) were studied in order to understand the behavior of PDMMLAs hydrolysis. Three homopolymers and three copolymers were analyzed for this study. The homopolymers have been investigated to understand the PDMMLAs degradation behavior under physiological conditions and the copolymers for their eventual use as a coating cardiovascular stent for the treatment of restenosis [93]. 


\subsubsection{Degradation of homopolymers: effect of load and nature of functional side chain and biological enzymes}

The degradation time of all PDMMLA homopolyesters was affected by the nature of side chain of PDMMLA $(-\mathrm{OH},-\mathrm{COOH}$, or hexyl). It was known that the hydrolysis process begins with the penetration of water into the polymer chains, followed by cleavage of ester functions and dissolution of degradation products. In the case of the hexylic homopolymer $(0 / 100)$ which is waterinsoluble, the diffusion of water within the polymer structure was hard due to the presence of the hydrophobic hexylic side chain. On the contrary, the carboxylic acidic group of acid hydrophilic homopolymer PDMMLA-COOH $(100 / 0)$ and the alcohol group of neutral hydrophilic homopolymer PDMMLA$\mathrm{OH}$ facilitated the diffusion of water molecules through their chains with their hydrophilic character and water-solubility of degradation products. Moreover, PDMMLA-COOH has negatively charged groups at $\mathrm{pH} 7.4$ which accelerated the hydrolytic degradation in comparison with PDMMLA-OH. Indeed, they have different degradation rate. Homopolymer P2' $(0 / 100)$ has a slower degradation rate while PDMMLA-COOH $(100 / 0)$ has the most rapid rate of degradation. PDMMLA-OH has a slower molecular weight loss rate in comparison to PDMMLA-COOH (Figure 17) [93].

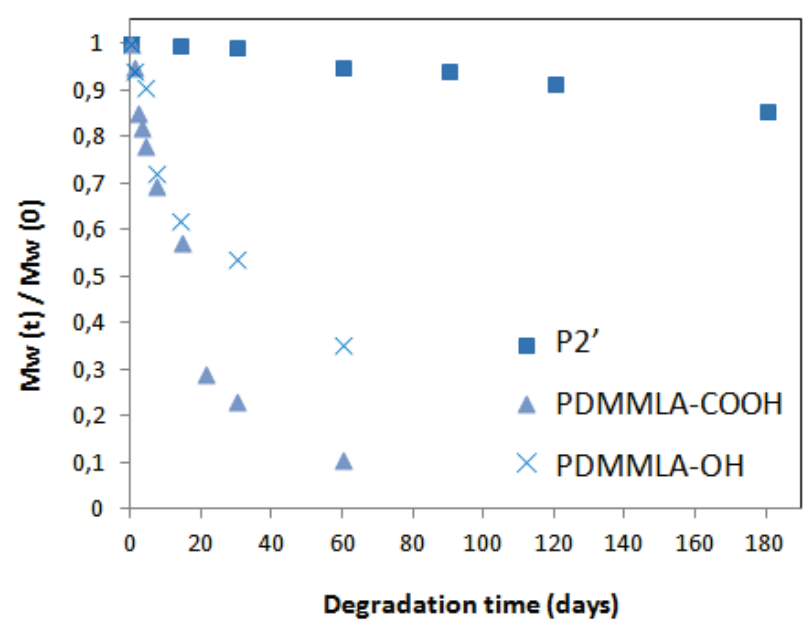

Figure 17. Molecular weight loss data for homopolymers (P2', PDMMLA-COOH, and PDMMLA-OH) in PBS at $\mathrm{pH} 7.4$ and $37^{\circ} \mathrm{C}$ [93]

Because of the presence of the functional group in the side chains of PDMMLA polymers comparing with other aliphatic polyesters such as PLA, their degradation behavior may be different. This deference can be observed by the slow degradation of the polymer chains indicated by an increase of the retention time with the presence of a single peak or with the presence of 
others picks with a smaller molecular weight. It was showed that all PDMMLA homopolymers were hydrolyzed with the formation of a second peak corresponding to small molecular weight and indicating a mixed degradation type in bulk and surface corrosion compared with PLA degradation which was rather in bulk [93]. The ratio of this second peak increased with the decrease of the ratio of the first peak over time. At pH 7.4, PDMMLA-COOH can be in the form of both protonated $(-\mathrm{COOH})$ and deprotonated $\left(-\mathrm{COO}^{-}\right)$groups. In this case, ionic interactions and hydrogen bonds with environment were observed. However, only hydrogen bonds were observed for PDMMLA-OH. Thus, the concentration of absorbed water was higher for PDMMLA-OH than PDMMLA$\mathrm{COOH}$ which explained, respectively, the observed bulk and corrosion degradation profiles.

In addition, in the presence of esterase, PDMMLA homopolymers can be degraded faster than the other conditions (in the presence or absence of $\alpha$ amylase). Therefore, selected esterase was involved in the ester bond hydrolysis of the studied homopolymers.

\subsubsection{Degradation of copolymers: effect of molecular weight, enzymes, $\mathrm{pH}$, and temperature}

Figure 18A showed the molecular weight loss of three copolymers having high molecular weights $\left(h M_{\mathrm{w}}\right)$ (Table 4$)$ as a function of degradation time. In a logical order, the degradation was faster with the material containing the highest ratio of hydrophilic side chain $\left(30 / 70_{h M w}\right)$; then a medium degradation rate was observed with the material having the medium ratio of $-\mathrm{COOH}$ groups $\left(20 / 80_{h M w}\right)$ and with that having the lowest ratio of $-\mathrm{COOH}\left(10 / 90_{h M w}\right)$, the degradation slowed further [93]. 

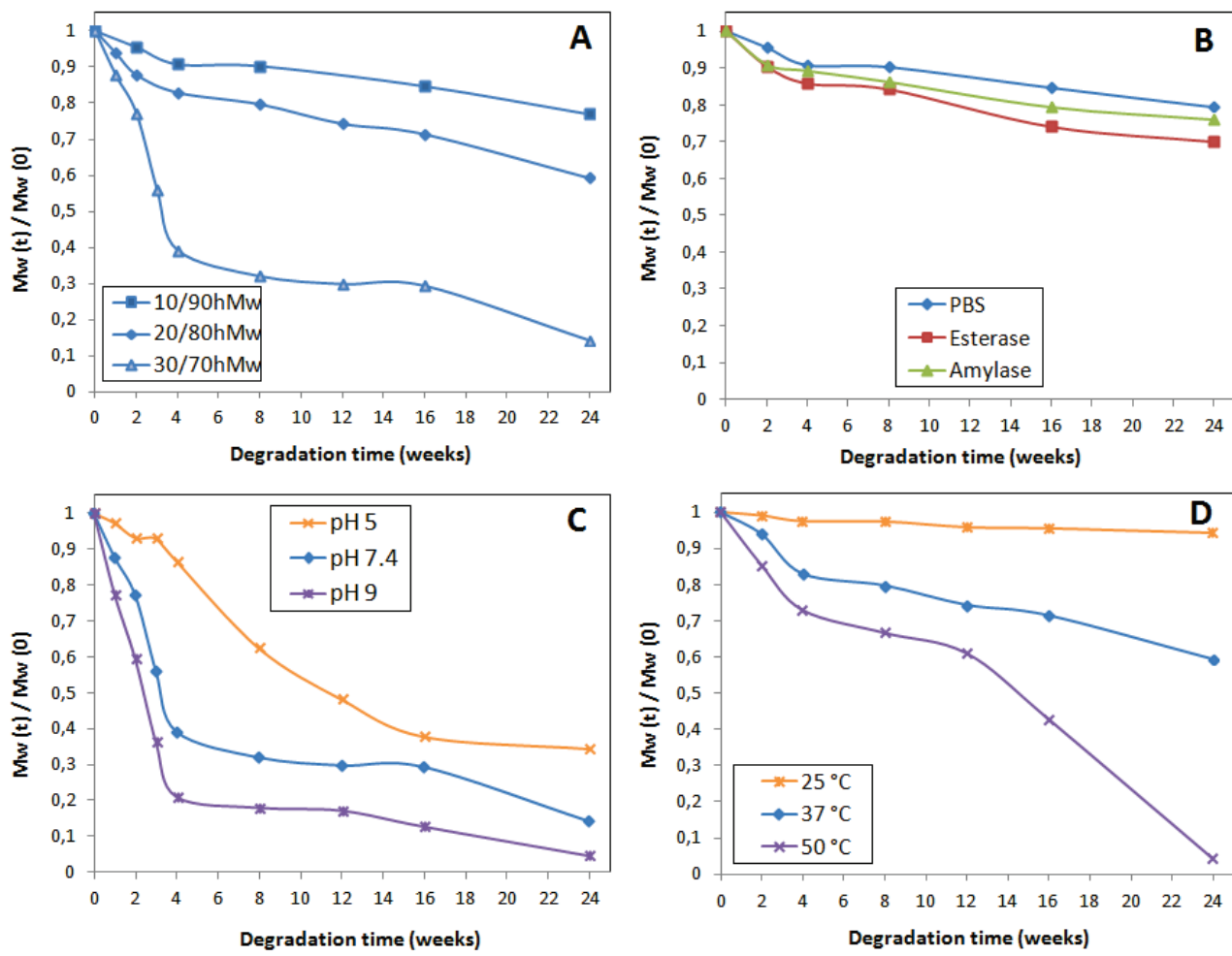

Figure 18. Molecular weight loss of $h M_{\mathrm{w}}$ copolymers: (A) hydrolysis in physiological conditions, (B) effect of enzymes on $h M_{\mathrm{w}}$ copolymers, (C) effect of $\mathrm{pH}$, and (D) effect of temperature [93]

The effect of molecular weight, enzymes, $\mathrm{pH}$, and temperature on the degradation nature and rate of the different copolymers was studied (Figures 18 and 19). It has been shown that the different PDMMLA copolymers were degraded according to bulk or erosion-surface profiles. Therefore, a hydrophilic loaded side chain, high temperature, high $\mathrm{pH}$, and the presence of specific enzyme accelerated the degradation rate of PDMMLAs with an erosion-surface profile.

\section{Effect of molecular weight}

The effect of molecular weight is evaluated in PBS at $\mathrm{pH} 7.4$ and $37^{\circ} \mathrm{C}$ on a series of three systems having the same ratio of hydrophilic/hydrophobic groups with two different initial molecular weights $\left(M_{\text {th }} \sim 23000 \mathrm{~g} \mathrm{~mol}^{-1}\right.$ and $230000 \mathrm{~g} \mathrm{~mol}^{-1}$ ).

It is important to compare the rate of degradation of the material having $\left(h M_{\mathrm{w}}\right)$ and that having the lowest ones $\left(I M_{\mathrm{w}}\right)$. Indeed, it was found that the polymer having $h M w$ and only $10 \%$ of $-\mathrm{COOH}\left(10 / 90_{h M w}\right)$ had similar degradation 
profile as compared to $10 / 90$ with $l M_{\mathrm{w}}$. It was slightly faster degraded by a linear greater molecular weight loss than $10 / 90$ over time $(\sim 3.5 \%)$ (Figure 19) [93].
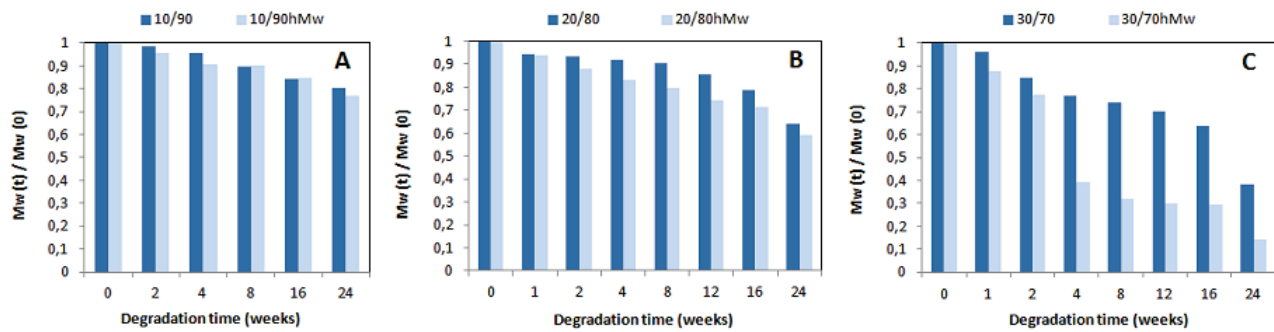

Figure 19. Effect of molecular weight on molecular weight loss and degradation rate and profile of $h M_{\mathrm{w}}$ copolymers: (A) 10/90 and 10/90 $h M_{\mathrm{w}}$, (B) 20/80 and 20/80 $h M_{\mathrm{w}}$, and (C) $30 / 70$ and $30 / 70_{h M w}[93]$

When $10 \%$ of acidic groups were added to the side chain of the copolymer $\left(20 / 80_{h M w}\right)$, it hydrolyzed with a double speed as compared to $10 / 90_{h M w}$ and a linear greater molecular weight loss as compared to its $I M_{\mathrm{w}}$ counterpart. Moreover, when the amount of acid is increased by another $10 \%\left(30 / 70_{\mathrm{hMw}}\right)$, the copolymer lost its weight very quickly in the first month and then slowed after. It had an equivalent molecular weight to the initial molecular weight of $30 / 70$ within the $6^{\text {th }}$ month. The present analysis of the behavior of degraded materials is very important because it gave an idea of the cleavage under physiological conditions of copolymer chains which have different molecular weights. This suggested that in the presence of such systems (PDMMLA copolymers) having an average molecular weight $\left(M_{\mathrm{th}} \sim 23000\right)$ the molecular weight loss was found linear with $R^{2}=0.96,0.95$, and 0.93 for 10/90, 20/80, and 30/70, respectively. On the other hand, with $h M_{\mathrm{w}}\left(M_{\mathrm{th}} \sim 230.000\right)$, the linearity was decreased with the increase of acids percentage. $R^{2}=0.94$ and 0.93 were obtained for $10 / 90$ and 20/80, which indicates linearity of degradation despite the slight weight loss. In contrast, with $30 \%$ of acid groups, the molecular weight loss was not linear $\left(R^{2}=0.69\right)$. This can be interesting for the selection of such type of materials having different molecular weight and hydrophilic/hydrophobic balance and thus different hydrolysis profiles [93].

\section{Effect of enzymes}

The effect of enzymes (esterase and $\alpha$-amylase) on the copolymers was performed on copolymers with low molecular weight $(l M \mathrm{w})$. The $\alpha$-amylase and esterase activities follow the same format as homopolymers. They were hydrolyzed with the same logic in the absence or presence of both enzymes. In 
all cases (PBS, esterase, and $\alpha$-amylase), elution profile indicated two major peaks. This result suggested the fragmentation of the inside and the outside of polymer's structure. With the same logic, the hydrolysis of $h M_{\mathrm{w}}$ copolymer $10 / 90_{h M w}$ was performed at $\mathrm{pH} 7.4$ and $37^{\circ} \mathrm{C}$ in the absence or presence of esterase and $\alpha$-amylase (Figure 18B) [93]. The same results were obtained.

\section{Effect of $p H$}

The effect of $\mathrm{pH}$ on the degradation of film of polymers is evaluated on the $30 / 70_{h M w}$ films with varying $\mathrm{pH}$ of hydrolysis medium: $5,7.4$, and 9 (Figure 18C). PDMMLA copolymers have carboxylic acid groups in their side chain which are capable of undergoing protonation/deprotonation depending on the environmental $\mathrm{pH}$. At $\mathrm{pH}$, copolymer has the slower degradation rate as compared to $\mathrm{pH} 7.4$ in the $6^{\text {th }}$ month. This effect was explained by the unionization of acidic groups at low $\mathrm{pH}$; they are sufficiently protonated at $\mathrm{pH}$ 5, noting "the acid inhibitory effects" [93]. At pH 9, the opposite behavior was observed. Indeed, $100 \%$ of molecular weight loss was observed in the

$6^{\text {th }}$ month. This was explained by the rapid degradation of film surfaces of copolymer which have in this time deprotonated groups (-COO-). Hydrolytic rate of copolymer increased with the increase of medium $\mathrm{pH}$. Thus the hydrolytic degradation of PDMMLA copolymers was $\mathrm{pH}$-sensitive. This result is according to literature studies on the polyesters degradation such as PLA and PLGA $[130,131]$.

Herein, we could conclude that, in low $\mathrm{pH}$, the hydrolysis has a bulk profile (diffusion of water molecules into polymer) in contrast to that in high $\mathrm{pH}$ which has an erosion-surface profile (degradation rate of polymer was faster than diffusion of water molecules). Moreover, at $\mathrm{pH} 7.4$, hydrolysis has a mixed profile "bulk and surface erosion" [93].

\section{Effect of temperature}

To evaluate the effect of temperature on the degradation of PDMMLAs copolymers, the hydrolysis of $20 / 80_{h M w}$ copolymer was carried out in PBS at $\mathrm{pH} 7.4$ at 3 different temperatures: 25,37 , and $50^{\circ} \mathrm{C}$. Figure $18 \mathrm{D}$ showed the hydrolysis profiles at different temperature. The results showed that the molecular weight loss at $25^{\circ} \mathrm{C}$ was very small over hydrolysis time as compared to $37^{\circ} \mathrm{C}$ condition. When the temperature was also increased at $50{ }^{\circ} \mathrm{C}$, the copolymer was completely degraded. Thus, PDMMLA copolymers degradation was temperature-dependent. Their degradation time was accelerated with the increase of temperature. These results could be explained by the hydrophilic/hydrophobic balance of copolymer which exhibited $20 \%$ hydrophilic groups in their side chains. This balance arranges in specific interactions between hydrophilic and hydrophobic functions at a critical temperature. With a change of this temperature, the arrangement between 
these groups changes again which can change the interaction of material with aqueous environment and so accelerate/decrease its degradation [93].

In conclusion, it has been shown that the different PDMMLA polymers were degraded according to bulk or erosion-surface profiles. Therefore, a hydrophilic loaded side chain, high temperature, high $\mathrm{pH}$, and the presence of specific enzyme accelerated the degradation rate of PDMMLAs with an erosion-surface profile. Otherwise, at low $\mathrm{pH}$ and temperature, the degradation speed is slow indicating a bulk degradation type while under physiological conditions PDMMLAs degraded with a mixed profile [93].

\subsubsection{Cytotoxicity of PDMMLAs degradation products}

Since these new biomaterials as promising coating stent will be in direct contact with the arterial wall, their biocompatibility was evaluated in this study in human vascular endothelial cells which are essential for the repair of the arterial wall to inhibit multiple processes leading to in-stent restenosis. Indeed, the viability of all synthesized PDMMLAs (PDMMLA-COOH, PDMMLA$\mathrm{OH}$, and copolymers 10/90, 20/80, and 30/70) and diacid (synthesis precursor and final degradation product of PDMMLA polymers) was conducted using MTT and Live/Dead assays after $24 \mathrm{~h}, 48 \mathrm{~h}$, and $72 \mathrm{~h}$ of human vascular endothelial cells (HUVEC) incubation. For example, Figure 20 shows the obtained results with PDMMLA-COOH 100/0, copolymer 30/70, and diacid. For all samples the proliferation cell was comparable to control which has $100 \%$ viability. Consequently, the cells viability tests, MTT and Live/Dead, revealed that the products of long-term degradation of all PDMMLA polymers were non-cytotoxic [93]. 


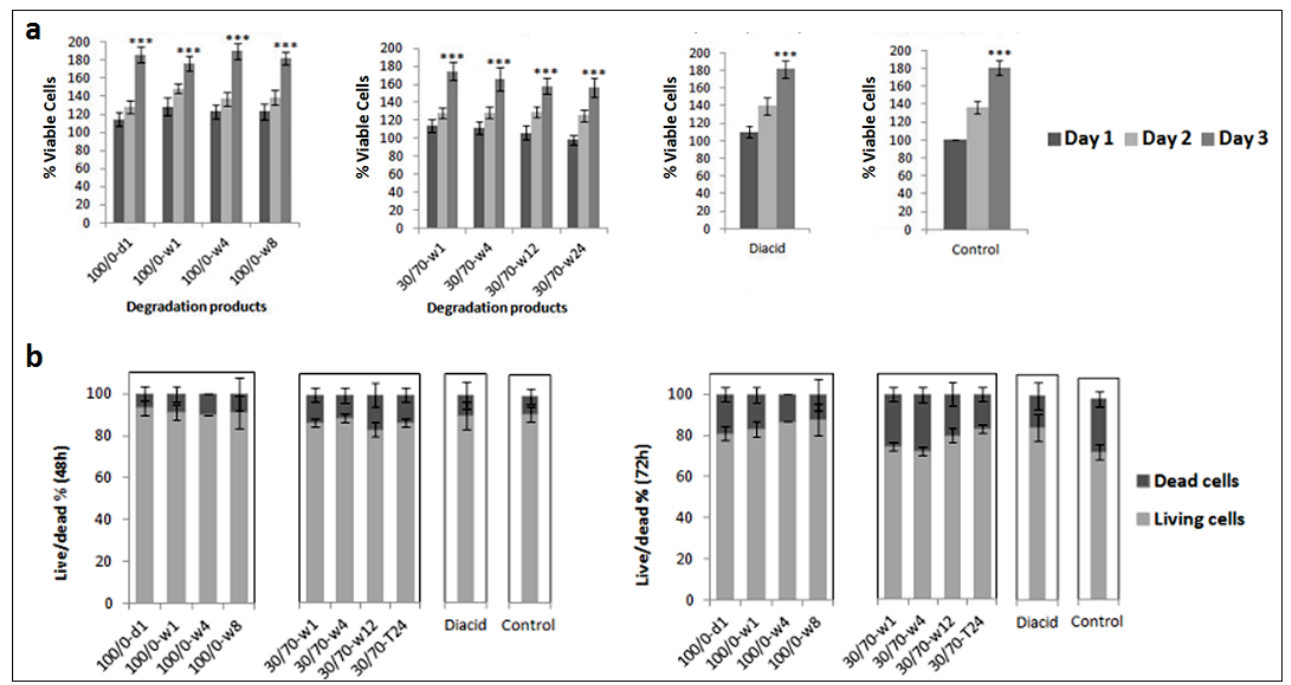

Figure 20. Cell viability of PDMMLA-COOH 100/0, copolymer PDMMLA-COOH/P2' $30 / 70$ degradation products, and diacid by (a) MTT test ( $d$ " indicated "day" and " $w$ " indicated "week"). Relative cell proliferation of HUVEC exposed for $24 \mathrm{~h}, 48 \mathrm{~h}$, and $72 \mathrm{~h}$ to all products of degradation. The values are represented as the mean value \pm SD $(n=3)$ where $*$ denotes significant changes between treated cells in $24 \mathrm{~h}$ and $72 \mathrm{~h}$ time with all degradation products. Here $(p<0.0001)$ ANOVA and (b) Live and Dead test obtained after $48 \mathrm{~h}$ and $72 \mathrm{~h}$ of incubation (" $d$ " indicated "day" and " $w$ " indicated "week") [93].

\subsection{CONCLUSION}

Since the active Drug Eluting Stents (DESs) that exist today have not been proven to reduce the risk of intrastent restenosis, the search for a new system is the aim of several research studies in recent years. Currently, most of the available DESs use a matrix polymer for both the coating of metal and the release of drugs. Although these polymers have brought benefits, certain adverse reactions occurred. Therefore, a growing number of studies in the field of biomaterials focused on the development of a new biodegradable, biocompatible, and bioassimilable polymer. These are the intrinsic properties of biodegradable aliphatic polyesters which are widely used as controlled release systems of drugs. Moreover, the polyester which has, in addition to these properties, the ability to be chemically modified and functionalisable is a challenge to achieve. PDMMLA is a new biodegradable and biocompatible polyester which can particularly be chemically modified. This chapter presented the history of this polyester as well as its interests in the biomedical field including the cardiovascular field. The surface properties of the PDMMLA derivatives were further discussed in this chapter. This allows choosing the best material for its study of biocompatibility on vascular cells and thus its use 
as stent coating. In conclusion, the properties of PDMMLAs give them a particular quality compared to other polyesters described in the literature and used as a stent coating such as PLA which is the most used coating material. In addition, the presence of a chiral center in the repeating unit of PDMMLA allowed the obtention of a series of new stereocopolymers. Thereby, it varies the configurational nature of the polymer and modulates and adjusts physicochemical properties of the material (crystallinity, solubility, degradability, etc.) depending on the tacticity of the chain. Based on these properties, PDMMLA is an excellent biodegradable polymer which may prove to be useful and good candidate for various temporary biomedical applications.

\section{REFERENCES}

1. H.Y. Tian, Z.H. Tang, X.L. Zhuang, X.S. Chen, X.B. Jing. Prog. Polym. Sci. 37 (2011) 237-280.

2. K. Fu, D.W. Pack, A.M. Klibanov, R. Langer. Pharm. Res. 17 (2000) 100-106.

3. R. De Santis, A. Russo, A. Gloria, U. D'Amora, T. Russo, S. Panseri, M. Sandri, A. Tampieri, M. Marcacci, V.A. Dediu, C.J. Wilde, L. Ambrosio. J. Biomed. Nanotechnol. 11 (2015) 1236-1246.

4. Z.W. Huang, V. Laurent, G. Chetouani, J.Y. Ljubimov, E. Holler, T. Benvegnu, P. Loyer, S. Cammas-Marion. Int. J. Pharmaceutics 423 (2012) 84-92.

5. J.Y. Ljubimova, J. Portilla-Arias, R. Patil, H. Ding, S. Inoue, J.L. Markman, A. Rekechenetskiy, B. Konda, P.R. Gangalum, A. Chesnokova, A.V. Ljubimov, K.L. Black, E. Holler. J. Drug Target. 21 (2013) 956-967.

6. P. Loyer, S. Cammas-Marion. J. Drug Target. 22 (2014) 556-575.

7. A. Lanz-Landäzuri, A. Martïnez de Ilarduya, M. Garcï-Alvarez, Sn. Muñoz-Guerra. React. Funct. Polym. 81 (2014) 45-53.

8. Y. Qiao, X. Duan, L. Fan, W. Li, H. Wu, Y. Wang. J. Polym. Res. 21 (2014) 1-9.

9. P. McDonald, J. Lyons, L. Geever, C. Higginbotham. J. Mater. Sci. 45 (2009) 1284-1292.

10. S.-T. Schmitz-Hertzberg, W.C. Mak, K.K. Lai, C. Teller, F.F. Bier. J. Applied Polym. Sci. 130 (2013) 4219-4228.

11. L. Wang, X. Jia, Y. Chen, Y. Che, Z. Yuan. J. Biomed. Mater. Res. Part A 87A (2008) 459-469.

12. K.L. Lai, B. He, Z.W. Gu. Chinese J. Polym. Sci. 26 (2008) 177-186.

13. Y. Liu, W. Wang, J. Wang, Y. Wang, Z. Yuan, S. Tang, M. Liu, H. Tang. Colloids Surf. B: Biointerfaces 75 (2010) 370-376.

14. J. Qian, W. Xu, W. Zhang, X. Jin. Mater. Lett. 124 (2014) 313-317.

15. Y. Zhang, C. Ni, G. Shi, J. Wang, M. Zhang, W. Li. Med. Chem. Res. 24 (2015) 1189-1195.

16. H. Ding, G. Helguera, J.A. Rodriguez, J. Markman, R. Luria-Perez, P. Gangalum, J. Portilla-Arias, S. Inoue, T.R. Daniels-Wells, K. Black, E. Holler, M.L. Penichet, J.Y. Ljubimova. J. Control. Release 171 (2013) 322-329.

17. B.-S. Lee, M. Vert, E. Holler. Biopolymers Online. Wiley-VCH Verlag GmbH \& Co. KGaA (2005).

18. B. Gasslmaier, C.M. Krell, D. Seebach, E. Holler. Eur. J. Biochem. 267 (2000) 5101-5105. 
19. B. He, J.Z. Bei, S.G. Wang. Polym. Adv. Technol. 14 (2003) 645-652.

20. S.L. King, V.X. Truong, C. Kirchhoefer, A. Pitto-Barry, A.P. Dove. Green Mater. 2 (2014) 107-122.

21. Y. Huang, H.C.A. Ng, X.W. Ng, V. Subbu. J. Control. Release 193 (2014) 188-201.

22. R. Hill, A. Bagust, A. Bakhai, R. Dickson, Y. Dündar, A. Haycox, R.M. Mota,

A. Reaney, D. Roberts, P. Williamson. Health Technol. Assess. 8 (2004) 1-242.

23. T. Palmerini, G. Biondi-Zoccai, D. Della Riva, C. Stettler, D. Sangiorgi, F. D'Ascenzo, T. Kimura, C. Briguori, M. Sabatè, H.-S. Kim. Lancet 379 (2012) 1393-1402.

24. J. Daemen, P. Wenaweser, K. Tsuchida, L. Albrecht, S. Vaina, C. Morger, N. Kukreja, P. Juni, G. Sianos, G. Hellige. Lancet 369 (2007) 667-678.

25. A. Farb, A.P. Burke, F.D. Kolodgie, R. Virmani. Circulation 108 (2003) 1701-1706.

26. M. Joner, A.V. Finn, A. Farb, E.K. Mont, F.D. Kolodgie, E. Ladich, R. Kutys, K. Skorija, H.K. Gold, R. Virmani. J. Am. Coll. Cardiol. 48 (2006) 193-202.

27. A.V. Finn, F.D. Kolodgie, J. Harnek, L.J. Guerrero, E. Acampado, K. Tefera, K. Skorija, D.K. Weber, H.K. Gold, R. Virmani. Circulation 112 (2005) 270-278.

28. K. Kolandaivelu, R. Swaminathan, W.J. Gibson, V.B. Kolachalama, K.-L. Nguyen-Ehrenreich, V.L. Giddings, L. Coleman, G.K. Wong, E.R. Edelman. Circulation 123 (2011) 1400-1409.

29. A.M. Lincoff, J.J. Popma, S.G. Ellis, J.A. Hacker, E.J. Topol. J. Am. Coll. Cardiol. 19 (1992) 926-935.

30. R. Virmani, G. Guagliumi, A. Farb, G. Musumeci, N. Grieco, T. Motta, L. Mihalcsik, M. Tespili, O. Valsecchi, F.D. Kolodgie. Circulation 109 (2004) 701-705.

31. G.J. Adams, U. Baltazar, C. Karmonik, C. Bordelon, P.H. Lin, R.L. Bush, A.B. Lumsden, J.D. Morrisett. J. Magn. Reson. Imaging 22 (2005) 125-135.

32. J. Gunn, D. Cumberland. Eur. Heart J. 20 (1999) 1693-1700.

33. P. Pescatore, H.J. Meier-Willersen, B.C. Manegold. Endoscopy 29 (1997) 413-415.

34. P.A. Ribeiro, R. Gallo, J. Antonius, L. Mimish, R. Sriram, S. Bianchi, C.G. Duran. Am. Heart J. 125 (1993) 501-510.

35. S.H. Hofma, H.M. van Beusekom, P.W. Serruys, W.J. van Der Giessen. Curr. Interv. Cardiol. Rep. 3 (2001) 28-36.

36. C.L. Liu, P.K. Chu, G.Q. Lin, M. Qi. Surf. Coat. Technol. 201 (2006) 2802-2806.

37. A.S. Hoffman. J. Biomed. Mater. Res. 20 (1986) ix-xi.

38. A.S. Hoffman. Ann. N.Y. Acad. Sci. 516 (1987) 96-101.

39. E.-M. Hietala. Poly-L/D-lactide Stents as Intravascular Devices: An Experimental Study, Helsinki, 2004.

40. R. Hoffmann, G.S. Mintz, G.R. Dussaillant, J.J. Popma, A.D. Pichard, L.F. Satler, K.M. Kent, J. Griffin, M.B. Leon. Circulation 94 (1996) 1247-1254.

41. C. Indolfi, A. Mongiardo, A. Curcio, D. Torella. Trends Cardiovasc. Med. 13 (2003) 142-148.

42. J.R. Dorgan, H. Lehermeier, M. Mang. J. Polym. Environm. 8 (2000) 1-9.

43. K.D. Nelson, A. Romero, P. Waggoner, B. Crow, A. Borneman, G.M. Smith. Tissue Eng. 9 (2003) 1323-1330.

44. $\quad$ K.R. Rajagopal, A.R. Srinivasa. Int. J. Plast. 14 (1998) 945-967.

45. K.R. Rajagopal, A.R. Srinivasa, A.S. Wineman. Int. J. Plast. 23 (2007) 1618-1636. 
46. B.S. Lee, M. Vert, E. Holler. Water-soluble Aliphatic Polyesters: Poly(malic acid)s, Biopolymers Online. 3a, 2002.

47. C. Braud, C. Bunel, M. Vert. Polym. Bull. 13 (1985) 293-299.

48. S. Cammas, M.-M. Béar, L. Moine, R.l. Escalup, G. Ponchel, K. Kataoka, P. Guérin. Int. J. Biol. Macromol. 25 (1999) 273-282.

49. D. Domurado, P. Fournié, C. Braud, M. Vert, P. Guérin, F.O. Simonnet. J. Bioact. Compat. Polym. 18 (2003) 23-32.

50. O. Coulembier, P. Degée, P. Gerbaux, P. Wantier, C. Barbaud, R. Flammang, P. Guérin, P. Dubois. Macromolecules 38 (2005) 3141-3150.

51. X. Yang, J.J. Grailer, S. Pilla, D.A. Steeber, S. Gong. Bioconjugate Chem. 21 (2010) 496-504.

52. Y.F. Poon, Y. Cao, Y.B. Zhu, Z.M.A. Judeh, M.B. Chan-Park. Biomacromolecules 10 (2009) 2043-2052.

53. Z. Zhao, M. He, L. Yin, J. Bao, L. Shi, B. Wang, C. Tang, C. Yin. Biomacromolecules 10 (2009) 565-572.

54. Y. Ikada, H. Iwata, F. Horii, T. Matsunaga, M. Taniguchi, M. Suzuki, W. Taki, S. Yamagata, Y. Yonekawa, H. Handa. J. Biomed. Mater. Res. 15 (1981) 697-718.

55. C.S.K. Reddy, R. Ghai, V.C. Kalia. Bioresource Technol. 87 (2003) 137-146.

56. M.M. Bear, M.As. Leboucher-Durand, V. Langlois, R.W. Lenz, S. Goodwin, P. Guérin. React. Funct. Polym.34 (1997) 65-77.

57. M.M. Bear, E. Renard, S. Randriamahefa, V.R. Langlois, P. Guérin. Comptes Rendus de l'Académie des Sciences - Series IIC - Chem. 4 (2001) 289-293.

58. N. Kurth, E. Renard, F. Brachet, D. Robic, P. Guerin, R. Bourbouze. Polymer 43 (2002) 1095-1101.

59. J.Y. Ljubimova, M. Fujita, A.V. Ljubimov, V.P. Torchilin, K.L. Black, E. Holler. Nanomedicine 3 (2008) 247-265.

60. M. Vert, R.W. Lenz. ACS Polym. Prepr. 20 (1979) 608-611.

61. R.J. Pounder, A.P. Dove. Polym. Chem. 1 (2010) 260-271.

62. I. Taniguchi, W.A. Kuhlman, A.M. Mayes, L.G. Griffith. Polym. Int. 55 (2006) 1385-1397.

63. O. Coulembier, P. Degée, J.L. Hedrick, P. Dubois. Progr. Polym. Sci. 31 (2006) 723-747.

64. M. Vert. Polym. Degrad. Stability 59 (1998) 169-175.

65. M. Vert. Makromolekulare Chemie. Macromolecular Symposia 6 (1986) 109-122.

66. R.W. Lenz, P. Guerin. Functional polyesters and polyamides for medical applications of biodegradable polymers, Polymers in Medicine, Springer, 1983, 219-230.

67. R.W. Lenz, M. Vert. Malic acid polymers, US Patents, 1981.

68. P. Guerin, J. Francillette, C. Braud, M. Vert. Macromol. Symp. 6 (1986) 305-314.

69. E. Renard, K. Boutault, V. Langlois, P. Guerin. Polym. Bull. 36 (1996) 585-592.

70. S. Cammas, K. Boutault, F. Huet, P. Guerin. Tetrahedron-Asymmetry 5 (1994) 1589-1597.

71. K. Boutault, S. Cammas, F. Huet, P. Guerin. Macromolecules 28 (1995) 3516-3520.

72. S. Cammas, M.A. Leboucher, I. Renard, K. Boutault, P. Guerin. Biodegr. Plast. Polym. 12 (1994) 534-540.

73. S. Cammas, M.M. Bear, L. Moine, R. Escalup, G. Ponchel, K. Kataoka, P. Guerin. Int. J. Biol. Macromol. 25 (1999) 273-282. 
74. C. Barbaud, S. Cammas-Marion, P. Guerin. Polym. Bull. 43 (1999) 297-304.

75. L. Moine, C. Amiel, W. Brown, P. Guerin. Polym. Int. 50 (2001) 663-676.

76. M.M. Bear, V. Langlois, D. Robic, R. Bourbouze, P. Guerin. J. Environm. Polym. Degrad. 7 (1999) 127-134.

77. P. Guérin, M. Vert. Polym. Commun. 28 (1987) 11-13.

78. C.T. Goodhue, E.E. Snell. Biochemistry 5 (1966) 403-408.

79. P.T. Magee, E.E. Snell. Biochemistry 5 (1966) 409-416.

80. M. Lähdesmäki, P. Mäntsälä. Biochimica et Biophysica Acta (BBA)-Enzymology 613 (1980) 266-274.

81. C. Barbaud, F. Abdillah, F. Faÿ, M. Guerrouache, P. Guérin. Design. Monom. Polym. 6 (2003) 353-367.

82. F. Ouhib, S. Randriamahefa, P. Guérin, C. Barbaud. Design. Monom. Polym. 8 (2005) 25-35.

83. C. Barbaud, M. Guerrouache, P. Guérin. Tetrahedron Lett. 43 (2002) 9513-9515.

84. P. Dowd, S.-C. Choi, F. Duah, C. Kaufman. Tetrahedron 44 (1988) 2137-2148.

85. K.S. Bhat, K.N. Dixit, A.S. Rao. Ind. J. Chem. Section B-Org. Chem. Incl. Med. Chem. 24 (1985) 509-512.

86. J.S. Bajwa, M.J. Miller. J. Org. Chem. 48 (1983) 1114-1116.

87. O. Mitsunobu. Synthesis 1 (1981) 1-28.

88. J. Mulzer, G. Brüntrup, A. Chucholowski. Angewandte Chem. Int. Ed. Eng. 18 (1979) 622-623.

89. R. Belibel, C. Barbaud. J. Polym. Science Part A-Polym. Chem. 53 (2015) 2586-2597.

90. R. Belibel, I. Azzouz, C. Barbaud. J. Polym. Sci.Part A-Polym. Chem. 54 (2016) 1495-1507.

91. V. Nurmikko, E. Salo, H. Hakola, K. Mäkinen, E.E. Snell. Biochemistry 5 (1966) 399-402.

92. C. Barbaud, F. Faÿ, F. Abdillah, S. Randriamahefa, P. Guérin. Macromol. Chem. Phys. 205 (2004) 199-207.

93. R. Belibel, N. Marinval, H. Hlawaty, C. Barbaud. Polym. Degrad. Stab. 130 (2016) 288-299.

94. M.A. LeboucherDurand, V. Langlois, P. Guerin. Polym. Bull. 36 (1996) 35-41.

95. F. Ouhib, S. Randriamahefa, P. Guerin, C. Barbaud. Design. Monom. Polym. 8 (2005) 25-35.

96. A. Lanz Landäzuri, M. Garcï-Alvarez, Sn. Muñoz-Guerra. Modification of microbial polyacids for drug delivery systems, Thesis for the $\mathrm{PhD}$, Barcelona, 2014.

97. R. Rai, T. Keshavarz, J.A. Roether, A.R. Boccaccini, I. Roy. Mater. Sci. Eng.: Reports 72 (2011) 29-47.

98. Y. Huang, H.C.A. Ng, X.W. Ng, V. Subbu. J. Control. Release 193 (2014) 188-201.

99. Etude des perspectives de développement des technologies textiles en ingénierie cellulaire et tissulaire, Dimetex, 2008.

100. A. Curtis, C. Wilkinson. Biomaterials 18 (1997) 1573-1583.

101. L. Ponsonnet, K. Reybier, N. Jaffrezic, V. Comte, C. Lagneau, M. Lissac, C. Martelet. Mater. Sci. Eng.: C 23 (2003) 551-560.

102. D. Klee, H. Höcker. Polymers for biomedical applications: improvement of the interface compatibility, Biomedical Applications Polymer Blends, Springer, 2000, p. 1-57. 
103. Y. Wang, P. Dong, L. Li, X. Li, H. Wang, X. Yang, S. Wang, Z. Li, X. Shang. Cardiovasc. Drugs Ther. 28 (2014) 379-385.

104. S.K. Jaganathan, E. Supriyanto, S. Murugesan, A. Balaji, M.K. Asokan. BioMed Res. Int. 2014 (2014) 1-11.

105. X.W. Ng, Y. Huang, K L. Liu, S.G. Lim, H.H. Chen, J.C. Burnett, F. Boey, Y. Chiang, S.S. Venkatraman. J. Pharm. Sci. 103 (2014) 3631-3640.

106. R. Belibel, T. Avramoglou, A. Garcia, C. Barbaud, L. Mora. Mater. Sci. Eng. C-Mater. Biol. Appl. 59 (2016) 998-1006.

107. R. Belibel, C. Barbaud, L. Mora. Mater. Sci. Eng.: C 69 (2016) 1192-1200.

108. S. Cammas-Marion, P. Guerin. Design. Monomers Polym.3 (2000) 77-93.

109. S. Cammas, I. Renard, K. Boutault, P. Guerin. Tetrahedron-Asymmetry 4 (1993) 1925-1930.

110. P. Guerin, M. Vert, C. Braud, R.W. Lenz. Polym.Bull. 14 (1985) 187-192.

111. M. Iida, S. Hayase, T. Araki. Macromolecules 11 (1978) 490-493.

112. R.A. Gross, Y. Zhang, G. Konrad, R.W. Lenz. Macromolecules 21 (1988) 2657-2668.

113. S. Bloembergen, D.A. Holden, T.L. Bluhm, G.K. Hamer, R.H. Marchessault. Macromolecules 22 (1989) 1656-1663.

114. A. Leborgne, N. Spassky. Polymer 30 (1989) 2312-2319.

115. J.E. Kemnitzer, S.P. McCarthy, R.A. Gross. Macromolecules 26 (1993) 1221-1229.

116. M. Arcana, O. Giani-Beaune, F. Schue, W. Amass, A. Amass. Polym. Int. 49 (2000) 1348-1355.

117. Y. Hori, T. Hagiwara. Int. J. Biol. Macromol. 25 (1999) 237-245.

118. M. Allmendinger, R. Eberhardt, G.A. Luinstra, B. Rieger. Macromol. Chem. Physics 204 (2003) 564-569.

119. M. Vert, S.M. Li, G. Spenlehauer, P. Guerin. J. Mater. Sci.: Mater. Med. 3 (1992) 432-446.

120. M. Trollsas, J.L. Hedrick. J. Am. Chem. Soc. 120 (1998) 4644-4651.

121. M. Trollsas, H. Claesson, B. Atthoff, J.L. Hedrick. Angewandte Chem.-Int. Ed. 37 (1998) 3132-3136.

122. M. Trollsas, J.L. Hedrick, D. Mecerreyes, P. Dubois, R. Jerome, H. Ihre, A. Hult. Macromolecules 31 (1998) 2756-2763.

123. M. Trollsas, M.A. Kelly, H. Claesson, R. Siemens, J.L. Hedrick. Macromolecules 32 (1999) 4917-4924.

124. Y. Huang. Drug Eluting Stents: Anti-Inflammatory Approach To Prevent Restenosis After Stent Implantation, Leuven University Press, 2003.

125. H.J. Busscher, A.W.J. Van Pelt, P. De Boer, H.P. De Jong, J. Arends. Colloids Surf. 9 (1984) 319-331.

126. D.R. Gagnon, T.J. McCarthy. J. Appl. Polym. Sci. 29 (1984) 4335-4340.

127. Interfacial Chemistry, Operating manual DataPhysics OC, DataPhysics Instruments GmbH (2002) 1-4.

128. L. Ponsonnet, K. Reybier, N. Jaffrezic, V. Comte, C. Lagneau, M. Lissac, C. Martelet. Mater. Sci. Eng. C-Biomimetic Supramol. Syst. 23 (2003) 551-560.

129. S. Benni, T. Avramoglou, H. Hlawaty, L. Mora. BioMed Res. Int.l 2014 (2014) 679031-679031.

130. C.F. Van Nostrum, T.F. J. Veldhuis, G.W. Bos, W.E. Hennink. Polymer 45 (2004) 6779-6787.

131. S. Li, H. Garreau, M. Vert. J. Mater. Sci.: Mater. Med. 1 (1990) 198-206. 